Valarinho, L.; Sena-Cruz, J.; Correia, J.R.; Branco, F.A. (2017) "Numerical simulation of the flexural behaviour of composite glass-GFRP beams using smeared crack models." Composites Part B, 110: 336-350.

\title{
Numerical Simulation OF THE FleXural BeHA Viour OF COMPOSITE GlaSS-GFRP Beams Using Smeared Crack Models
}

\author{
Luís Valarinhoo ${ }^{a^{*}}$, José Sena-Cruz ${ }^{\mathrm{b}}$, João R. Correia ${ }^{\mathrm{a}}$ and Fernando A. Branco ${ }^{\mathrm{a}}$ \\ ${ }^{a}$ CERIS, Instituto Superior Técnico, Universidade de Lisboa, Lisboa, Portugal. \\ ${ }^{\mathrm{b}}$ ISISE, School of Engineering, University of Minho, Guimarães, Portugal. \\ * corresponding author: luis.valarinho@tecnico.ulisboa.pt
}

\begin{abstract}
This paper presents a numerical study about the flexural behaviour of rectangular composite glass-GFRP beams, comprising annealed glass and GFRP pultruded profiles bonded with two different adhesives: (soft) polyurethane and (stiff) epoxy. The main objectives of this study were: (i) to fully characterize the non-linear behaviour of glass using the smeared crack approach; and (ii) to assess the applicability of different options to simulate adhesively bonded glass-GFRP joints. An extensive parametric study was developed to evaluate the influence of five parameters on the glass post-cracking non-linear behaviour: (i) glass fracture energy, $G_{f}$, (ii) crack band width, $h$, (iii) glass tensile strength, $f_{g, t}$ (iv) shape of the tension-softening diagram, and (v) shear retention factor, $\beta$. The wide range of the joints' shear stiffness was simulated by either (i) assuming a perfect bond between glass and GFRP (i.e., neglecting the presence of the adhesive), or (ii) explicitly considering the adhesive, by means of using (ii.1) plane stress elements, or (ii.2) interface elements. For the beams analysed in this paper, the following material model for glass provided a good agreement with experimental results: $G_{f}$ in the range of 3 to $300 \mathrm{~N} / \mathrm{m}, h$ equal to the square root of the finite element area, $f_{g, t}=50 \mathrm{MPa}$, linear softening diagram and $\beta$ according to a power law. It was also shown that the hypothesis of perfect bond at the GFRP-glass interfaces allows for an accurate simulation of joints with high levels of interaction (epoxy), while calibrated interface elements are needed for joints with low level of interaction (polyurethane).
\end{abstract}

Keywords: Glass-GFRP composite beams; numerical analysis; smeared crack approach; adhesively bonded joints; interface elements; parametric study. 
Valarinho, L.; Sena-Cruz, J.; Correia, J.R.; Branco, F.A. (2017) "Numerical simulation of the flexural behaviour of composite glass-GFRP beams using smeared crack models." Composites Part B, 110: 336-350.

\section{Introduction}

Over the last decades the structural use of glass has become one of the most interesting topics in construction industry and civil engineering research, following the architectural trend of pursuing more creative and transparent building envelopes. As a result, besides the common use in glazed facades, glass has assumed more important structural roles, for instance in floors, ceilings, beams or columns. However, due to the brittle nature of glass and the high scatter of its strength it is necessary to adopt special structural safety measures.

For beam applications, one of the methods that has been put forward to overcome glass brittleness is the use of hybrid glass systems (also referred to as composite or reinforced systems [1,2]): the underlying principle is based on reinforced concrete, where a brittle and relative weak material in tension (glass) is combined with other structural materials, generally stronger in tension, in order to enhance the pre- and post-cracking performance. In most of the hybrid concepts $[1,2]$, it has been experimentally shown that composite or reinforced glass beams provide significant improvements in terms of post-cracking resistance and ductility, leading to less brittle failure mechanisms compared to all-glass beams.

In spite of such achievements, composite glass systems are not yet being used on a regular basis in industrial applications. Among other reasons, this is due to the lack of reliable analysis and design tools $^{1}$. Because geometrical shapes and material (glass) responses can be rather complex, finite element (FE) models are useful tools to assist the structural design of composite glass members. In this respect, the main challenge relies on the ability to accurately model (i) the fracture behaviour of glass, a brittle material, often causing numerical instabilities, and (ii) the interaction between glass and the reinforcing materials.

This paper presents a numerical study about the flexural behaviour of composite beams made of annealed glass panes and GFRP pultruded laminates. After a short literature review about the

\footnotetext{
${ }^{1}$ The recent Italian guidelines [29] and the recent British and European guidance for structural glass [26,30] do not provide information about the analysis and design of reinforced or composite glass beams.
} 
Valarinho, L.; Sena-Cruz, J.; Correia, J.R.; Branco, F.A. (2017) "Numerical simulation of the flexural behaviour of composite glass-GFRP beams using smeared crack models." Composites Part B, 110: 336-350.

numerical modelling of composite glass beams (Section 2), the paper first summarizes an experimental campaign about the pre- and post-cracking flexural behaviour of rectangular glassGFRP composite beams bonded with two different adhesives (Section 3): (soft) polyurethane and (stiff) epoxy. The campaign included also tensile tests on double-lap joints performed to characterize the interface constitutive law for both adhesives. The second part of the paper (Sections 4 and 5) describes the numerical models developed to simulate the flexural behaviour of the aforementioned beams. Two-dimensional (2D) FE models were developed using the FEMIX software [3] in order to simulate and analyse the linear (prior to glass breakage) and post-cracking flexural behaviour of the glass-GFRP composite beams. A multi-fixed smeared crack model was used to simulate the nonlinear material behaviour of glass. The objective of the numerical study was two-fold: (i) the definition of the parameters that describe the non-linear material response of glass, and (ii) the evaluation of different options to simulate adhesively bonded interfaces. Experimental and numerical results are compared in terms of initial stiffness, cracking load, post-cracking stiffness, crack pattern and progressive failure of the glass-GFRP composite beams.

\section{Literature review}

For now, only a few studies addressed the numerical simulation of hybrid glass systems. The existing ones can be divided according to the approach adopted to simulate the (quasi-) brittle glass material: (i) the "kill element" approach (KEA); (ii) the smeared crack approach (SCA), and (iii) the discrete crack approach (DCA).

The "kill element" approach was applied by Ølgaard et al. [4] and Louter and Nielsen [9] using a commercial FE-package (with the addition of user-subroutines) and tested on two (2D) and three dimensional (3D) FE models of reinforced glass-stainless steel beams with SentryGlas ${ }^{\circledR 2}[6,7]$. The different models were tested with several mesh densities, with constant and random glass tensile

\footnotetext{
${ }^{2}$ SentryGlas ${ }^{\circledR}$ was used both as interlayer and as structural adhesive [6].
} 
Valarinho, L.; Sena-Cruz, J.; Correia, J.R.; Branco, F.A. (2017) "Numerical simulation of the flexural behaviour of composite glass-GFRP beams using smeared crack models." Composites Part B, 110: 336-350.

strengths and with different interlayer shear stiffness values. The models were able to correctly reproduce the overall load $v s$. deflection behaviour of the composite glass beams. The 2D models accurately reproduced the crack pattern. However, the 3D models were not able to simulate precisely the three-dimensional process of cracking, as cracks were predicted to occur uniformly across the whole cross-section thickness instead of being randomly distributed. Despite the good results and the simplicity of its principles, this approach does not exist in the most popular commercial FE packages and hence it needs to be developed and added by users.

The SCA has been used for decades to numerically reproduce the cracked stage of reinforced concrete and other quasi-brittle materials. According to Bazant and Oh [8], two main assumptions ${ }^{3}$ are made in this numerical approach: (i) the damaged area is distributed along a specific crack band width $(h)$, and (ii) the constitutive law of the material in the damage area is characterized by a tension-softening diagram, which, together with the fracture energy $\left(G_{f}\right)$, are considered material properties and important input data. Regarding the $G_{f}$ of glass, experimentally determined in [9-11], an average value of $3 \mathrm{~N} / \mathrm{m}$ is commonly accepted $[6,12,13]$. This is an extremely low value when compared with other quasi-brittle ${ }^{4}$ materials (e.g. it is around 30 times lower than that of concrete $[14,15]$ ) to which SCA have been applied. The SCA approach also requires several other parameters, including the type of tension-softening diagram, the shear retention factor $(\beta)$ and the number of possible cracks that can arise in each single integration point [16].

Louter [6] and Bedon and Louter [13] used the SCA to numerically simulate the behaviour of reinforced glass-stainless steel beams. Using 2D and 3D models, the authors performed parametric studies to assess the effects of $G_{f}$, mesh size, mesh geometry, $\beta$, shear stiffness of the SentryGlas ${ }^{\circledR}$

\footnotetext{
${ }^{3}$ The fracture energy criterion and the existence of a softening branch are also assumed by DCA.

${ }^{4}$ Applying the SCA to glass requires the assumption that the stable fracture of glass [9-11] is equivalent to the quasi-brittle behaviour of concrete. In true, glass is known to be a homogeneous brittle material that only presents stable fractures (or softening, in analogy to concrete) under very specific situations [9]. Moreover, it should be noted that the stable fracture of glass falls in the linear elastic fracture mechanics field, whereas concrete softening of lab-size specimens falls mostly (it depends on the relationship between the crack size and the size of the adjacent fractured zone) on the non-linear fracture mechanics field [31]. Other terms have been used to describe the stable fracture of glass (e.g., in Haldiman et al. [12] framed it in the "quasi-brittle linear elastic fracture mechanics").
} 
Valarinho, L.; Sena-Cruz, J.; Correia, J.R.; Branco, F.A. (2017) "Numerical simulation of the flexural behaviour of composite glass-GFRP beams using smeared crack models." Composites Part B, 110: 336-350.

and reinforcement ratio in the overall flexural behaviour of the reinforced beams and in their crack pattern type and propagation [6,13]. It was shown that $G_{f}($ ranging from $3 \mathrm{~N} / \mathrm{m}$ to $8 \mathrm{~N} / \mathrm{m}$ ), mesh size (square finite elements with 5 and $10 \mathrm{~mm}$ of size for a total span of 1500 and $3200 \mathrm{~mm}$ ), $\beta$ (with constant values or power laws) or the shear stiffness of the interlayer (varying from $240 \mathrm{MPa}$ to $20 \mathrm{GPa}$ ) have minor influence on the overall flexural behaviour of the aforementioned beams (only crack pattern differences were noticeable). In opposition, the mesh geometry (and the reinforcement ratio) proved to have significant influence on the global behaviour of the beams and on their crack pattern. Notwithstanding the good match between numerical and experimental results, on the one hand Louter [5] used a numerical strategy to overcome glass brittleness ("saw-tooth" reduction diagrams) that is far from being universally accepted; on the other hand, Bedon and Louter's [12] models were computationally very demanding.

The discrete crack approach (DCA) was successfully applied by Neto et al. [17] to model the flexural behaviour of glass-GFRP composite beams. A parametric study was developed to assess the ability of the DCA to represent glass cracking taking into account the influence of the mesh size and glass tensile strength $\left(f_{g, t}\right)$. It was proved that using DCA both mesh size and $f_{g, t}$ have minor influence on the global behaviour of the numerical models of the composite beams. The major disadvantage of the DCA is its low popularity compared to the SCA and the fact that it is not available in most commercial FE packages.

The extreme brittleness of glass, i.e., the very low value of $G_{f}$, causes numerical problems like snapback instabilities or convergence difficulties. Typically, these problems are overcome by either (i) applying numerical tools or strategies that help models to converge (e.g. the above-mentioned "sawtooth" reduction diagrams), (ii) non-iterative methods [17], (iii) or by developing heavy computational models in terms of mesh density [13]. In spite of the above mentioned limitations, none of the numerical studies reviewed above in which the SCA or the DCA were used has assessed the possibility or the effects of adopting fracture energies higher than the reference value for glass in reinforced or composite glass beams (the maximum $G_{f}$ used in those numerical models was $8 \mathrm{~N} / \mathrm{m}[6,13]$ ).

Furthermore, in the aforementioned studies only two types of hybrid systems were simulated: (i) 
Valarinho, L.; Sena-Cruz, J.; Correia, J.R.; Branco, F.A. (2017) "Numerical simulation of the flexural behaviour of composite glass-GFRP beams using smeared crack models." Composites Part B, 110: 336-350.

glass-stainless steel (bonded with SentryGlas ${ }^{\circledR}$ ), and (ii) glass-GFRP composite beams (bonded with epoxy adhesives). Therefore, with the single exception of the work of Neto et al. [17], none of the works have applied smeared crack models in combination with interface laws to numerically simulate the behaviour of the bonded interfaces in which a wide range of adhesives (with different mechanical properties) can be used. Note that the two types of adhesives that have been studied in [16] were considered stiff enough to neglect the potential slippage at the interfaces. The effect of using softer adhesives, although object of experimental studies [18,19], was never numerically investigated.

\section{Summary of experimental results}

This section presents a summary of the experimental campaign developed in order to assess (i) the shear behaviour of glass-GFRP adhesively bonded joints, and (ii) the flexural behaviour of glassGFRP composite beams. More detailed information about some of the experimental tests abridged here is available in [17-19].

\subsection{Structural concept}

The rectangular composite beams (Fig. 1) were made of annealed glass panes (cross section of $100 \times$ $12 \mathrm{~mm}^{2}$ ), reinforced at the bottom edge with a rectangular GFRP pultruded profile (cross section of $8 \times 12 \mathrm{~mm}^{2}$ ). The two materials were joined with a $2 \mathrm{~mm}$ thick bond layer, made of two different adhesives: (i) a low Young's modulus polyurethane adhesive, Sikaflex 265, and (ii) a high modulus epoxy adhesive, Sikadur 31-cf. 
Valarinho, L.; Sena-Cruz, J.; Correia, J.R.; Branco, F.A. (2017) "Numerical simulation of the flexural behaviour of composite glass-GFRP beams using smeared crack models." Composites Part B, 110: 336-350.

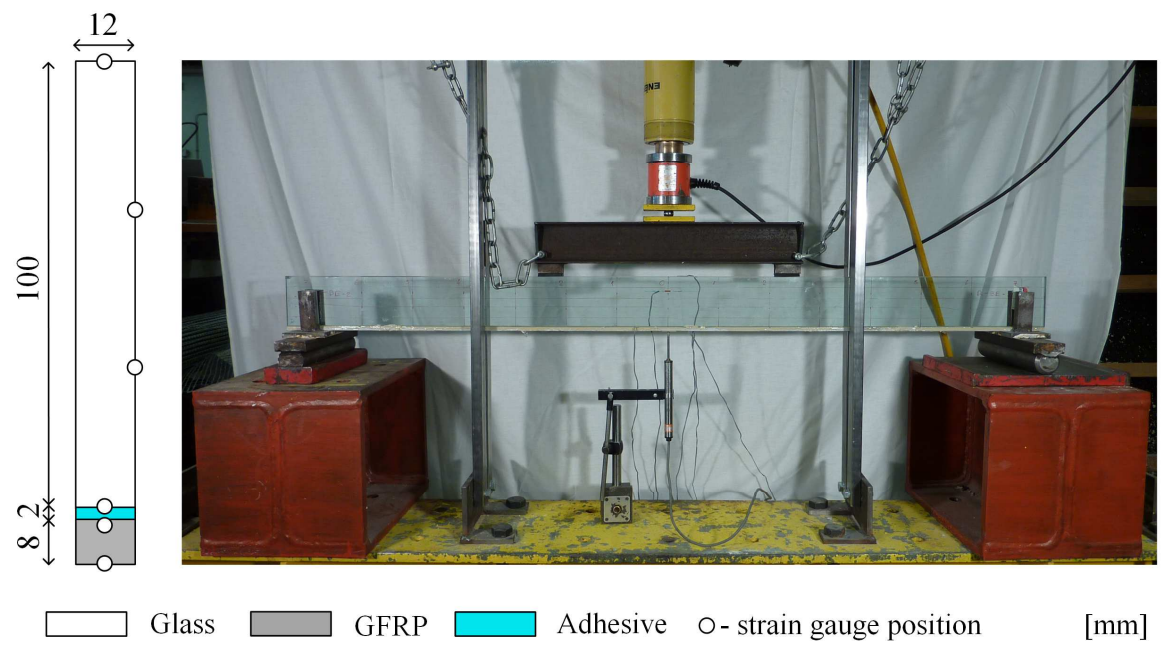

Fig. 1 - Cross section of the glass-GFRP composite beams and experimental setup.

\subsection{Materials}

Annealed glass panes (12 mm thick) with polished edges were used in the tests. The main mechanical properties of glass available in literature were considered. A detailed description of those properties is presented in section 4.3.1.

The GFRP profiles used to strengthen the glass beams were made of an isophthalic polyester matrix reinforced with alternating layers of E-glass rovings and mats. Tensile tests according to ISO 527-1,4 $[20,21]$ indicated an average Young's modulus of $32 \mathrm{GPa}$ and ultimate strength of $350 \mathrm{MPa}$ (in the longitudinal direction) [19].

The mechanical properties of the Sikaflex 265 and Sikadur 31-cf adhesives (hereafter referred to as SFlex and SDur) used to bond glass to the GFRP profiles are listed in Table 1. The former is a gapfilling adhesive (with similarities to rubber) and presents low elasticity modulus $\left(E_{a}\right)$, together with relatively high apparent ultimate stress $\left(f_{a, t}\right)$ and ultimate tensile elongation $\left(\varepsilon_{b}\right)$. The latter is a structural epoxy adhesive with negligible density of fillers and it is characterized by relatively high Young's modulus and tensile strength, and low ultimate strain. The adhesives were characterized in [17] according to their applicable standards, ISO 37 [22] (SFlex) and ISO 527-1,2 [20,23] (SDur). The Poisson's ratios were determined using a digital image correlation system, with the SFlex 
Valarinho, L.; Sena-Cruz, J.; Correia, J.R.; Branco, F.A. (2017) "Numerical simulation of the flexural behaviour of composite glass-GFRP beams using smeared crack models." Composites Part B, 110: 336-350.

presenting a high $v_{\text {SFlex }}=0.45$, whereas for the SDur adhesive, $v_{\text {SDur }}=0.25$.

Table 1 - Tensile mechanical properties of the adhesives $\left(E_{a}, f_{a, u}\right.$ and $\left.\varepsilon_{b}\right)$ and summary of results from doublelap joint tests $\left(K, F_{\max }, d_{\max }\right.$ and failure mode).

\begin{tabular}{l|ccc|cccc}
\hline \multicolumn{1}{c|}{ Adhesive } & \multicolumn{3}{|c|}{ Tensile tests } & \multicolumn{4}{c}{ Double-lap joint tests } \\
& $\boldsymbol{E}_{\boldsymbol{a}}[\mathbf{M P a}]$ & $\boldsymbol{f}_{\mathbf{a}, \mathbf{t}}[\mathbf{M P a}]$ & $\boldsymbol{\varepsilon}_{\mathbf{b}}[\boldsymbol{\%}]$ & $\boldsymbol{K}[\mathbf{k N} / \mathbf{m m}]$ & $\boldsymbol{F}_{\mathbf{m a x}}[\mathbf{k N}]$ & $\boldsymbol{d}_{\mathbf{m a x}}[\mathbf{m m}]$ & Failure mode \\
\hline Sikaflex 265 & $3.08 \pm 7 \%$ & $8.13 \pm 12 \%$ & $317 \pm 15 \%$ & $2.16 \pm 11 \%$ & $13.5 \pm 26 \%$ & $8.37 \pm 23 \%$ & adhesive \\
Sikadur 31-cf & $4257 \pm 16 \%$ & $11.7 \pm 22 \%$ & $0.21 \pm 42 \%$ & $85.0 \pm 3 \%$ & $30.3 \pm 14 \%$ & $0.46 \pm 12 \%$ & stock-break \\
& & & & & & glass) \\
\hline
\end{tabular}

\subsection{Tests on double lap joints}

In order to characterize the behaviour of adhesively bonded joints between glass and GFRP, double-lap joint specimens were prepared and tested in tension. The specimens geometry, test setup and procedure is described in detail in Valarinho et al. [19,24]. Some complementary tests are also included below. The joints comprised two inner GFRP laminates $\left(10 \times 50 \mathrm{~mm}^{2}\right)$ and two outer glass panes $(12 \times 50$ $\mathrm{mm}^{2}$ ), bonded with a $2 \mathrm{~mm}$ thick SFlex or SDur adhesive layer. Both adherends presented a length of $350 \mathrm{~mm}$ and the overlap length was set to $100 \mathrm{~mm}$ (Fig. 2-a). The complementary campaign consisted of five new joint specimens made of both SFlex and SDur adhesives (hereafter referred to as $D L$ SFlex-\# and DL-SDur-\#, respectively, where \# refers to the specimen number). The strain development along one of the bonded GFRP surfaces was measured using 10 strain gauges (Fig. 2b). Specimens were loaded under displacement control at a speed of $0.017 \mathrm{~mm} / \mathrm{s}$ (total displacement). The applied load and the relative displacement between bonded extremities of both overlap zones were measured during the tests. The tests were conducted at an average temperature of $19^{\circ} \mathrm{C}$ and relative humidity of $59 \%$. 
Valarinho, L.; Sena-Cruz, J.; Correia, J.R.; Branco, F.A. (2017) "Numerical simulation of the flexural behaviour of composite glass-GFRP beams using smeared crack models." Composites Part B, 110: 336-350.

a)

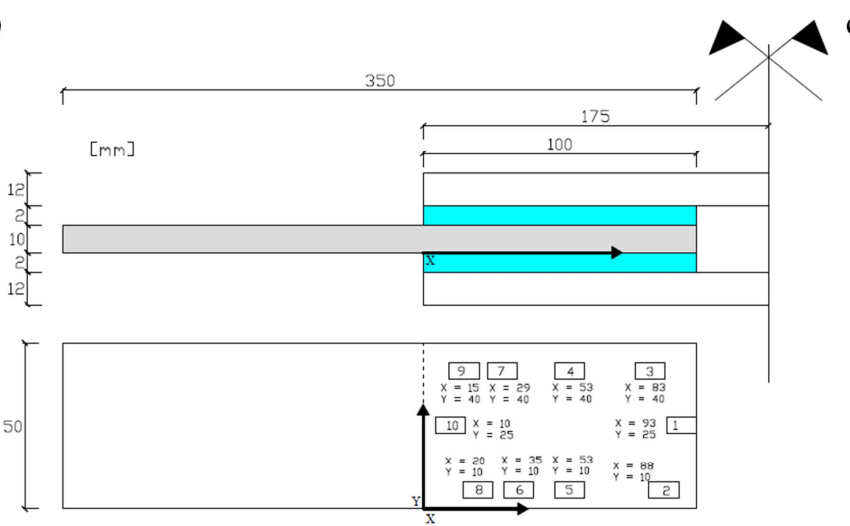

)

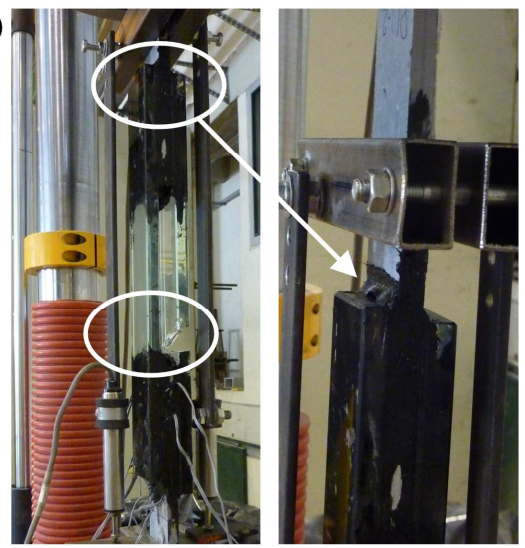

Adhesive \#- strain gauge position

Fig. 2 - Geometry of the double lap joints (a), position of the strain gauges (b) and (c) tensile test setup and failure mode of $D L$-SFlex specimens.

Fig. 3 depicts the load vs. relative displacement curves of DL-SFlex and DL-SDur specimens. Table 1 presents a comparison of the average results obtained for the different specimens, in terms of initial stiffness $(K)$, maximum load $\left(F_{\max }\right)$ and corresponding maximum relative displacement $\left(d_{\max }\right)$ and failure mode.

As reported in previous tests $[18,19,24]$, the behaviour of $D L$-SFlex joints was not fully consistent. On the one hand, specimens $D L$-SFlex-1,4 presented an initial linear behaviour, with loss of stiffness only at the brink of collapse. On the other hand, specimens DL-SFlex-2,3,5 exhibited a shorter linear branch and an earlier loss of stiffness that led to premature failure (Fig. Fig. 3-a). Accordingly, the ultimate loads exhibited relatively high scatter. The stiffness loss was due to the debonding in one of the glass-adhesive interfaces, which ultimately caused the failure of all joints (Fig. 2-c). The scatter of results may have been caused by the high viscosity of the adhesive, which affected the manual process used to manufacture the specimens. 
a)

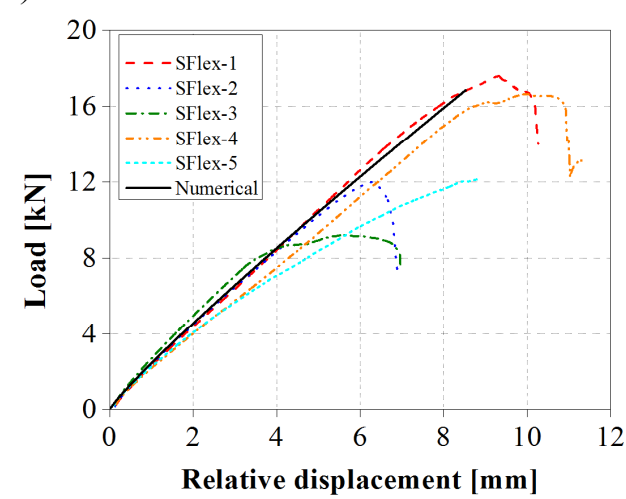

b)

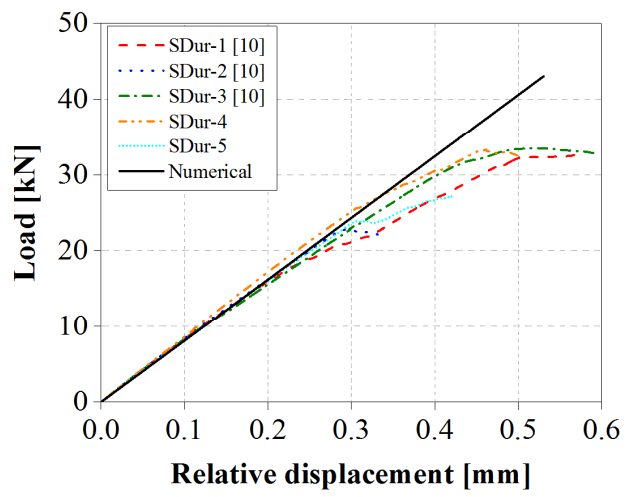

Fig. 3 - Results of double-lap joint tests: load vs. relative displacement for specimens (a) SFlex and (b) SDur.

DL-SDur specimens exhibited practically linear behaviour up to failure, without significant stiffness changes during loading (Fig. 3-b). The slight loss of stiffness prior to failure was coincident with the appearance of the first cracks on glass at the overlap region. After this point, all specimens were still able to carry additional load up to their ultimate failure, which occurred due to the breakage of one of the glass panes. The $K, F_{\max }$ and $d_{\max }$ values were in line with the corresponding adhesive mechanical properties. Comparing with the DL-SFlex joints, by avoiding the premature failure of one of the bonded interfaces, much higher stiffness ( $\approx 40$ times) and higher strength was observed in the DL-SDur joints. The axial strain distributions, reflecting the shear stress transfer between the joined components, were also coherent with the stiffness of the adhesives (Fig. 4): the distribution was roughly uniform for the softest adhesive and non-uniform with high concentrations at the extremities for the stiffest one.

a)

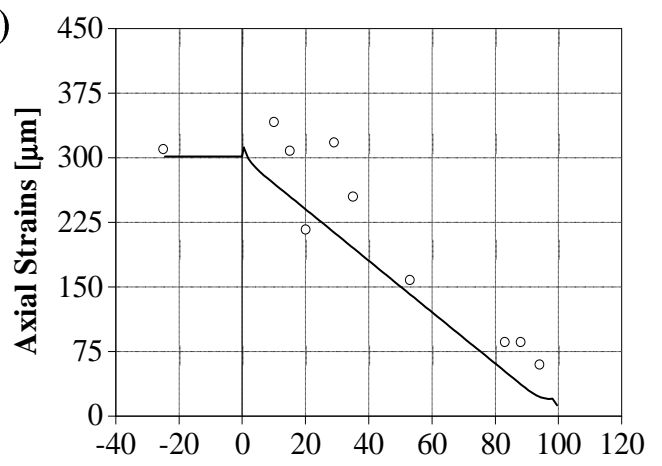

Location of the SG (coordinate $\mathrm{X}$ ) [mm] b)

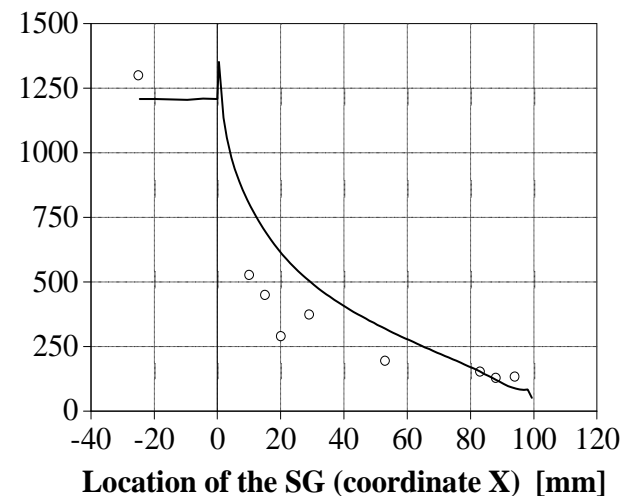

Fig. 4 - Experimental (dots) and numerical (lines) axial strains (a) at $5.0 \mathrm{kN}$ for $D L-S F l e x-2$ and (b) at $20 \mathrm{kN}$ for $D L$ - 
Valarinho, L.; Sena-Cruz, J.; Correia, J.R.; Branco, F.A. (2017) "Numerical simulation of the flexural behaviour of composite glass-GFRP beams using smeared crack models." Composites Part B, 110: 336-350.

SDur-4.

\subsection{Four-point bending tests}

Four-point bending tests were performed to assess the flexural behaviour of rectangular glass-GFRP composite beams, bonded with the two previously mentioned adhesives. The beams were $1.5 \mathrm{~m}$ long, with a span of $1.4 \mathrm{~m}$ and a shear span of $0.465 \mathrm{~m}$ (Fig. 1). The rectangular beams were transversally restrained with two pairs of metal guides symmetrically positioned throughout the span. Beams were loaded under indirect displacement control, applied by a Walter+Bai hydraulic system that allows controlling the pressure transmitted to the jack, capturing possible load drops and recoveries if the beams experience quasi-static damage. Hence, the displacement speed was indirectly controlled, as a result of the pressure applied on the jack and the response (flexural stiffness) of the beam. Therefore, the displacement speed ranged from $0.95 \mathrm{~mm} / \mathrm{min}$ to $1.52 \mathrm{~mm} / \mathrm{min}$ prior to cracking and, subsequently, from $1.70 \mathrm{~mm} / \mathrm{min}$ to $3.21 \mathrm{~mm} / \mathrm{min}$. The applied load and the mid-span displacement were measured at average speeds of $5 \mathrm{~Hz}$. The glass/GFRP interaction ensured by the adhesives was assessed measuring the longitudinal strains by means of six strain gauges bonded along the mid-span section height (Fig. 1) and in both interfaces (glass/adhesive and adhesive/GFRP). All beams were tested at an average temperature of $24^{\circ} \mathrm{C}$ and relative humidity of $60 \%$.

Fig. 5 presents the load $v s$. mid-span deflection curves of the composite beams bonded with the SFlex and $S D u r$ adhesives (hereafter referred to as $R$-SFlex and $R$-SDur, respectively). Both type of beams presented a similar behaviour, which can be divided in two stages: the first stage is characterized by a linear elastic behaviour until the appearance of the first crack in glass; in the second stage, a progressive loss of stiffness was visible either due to the development of a single glass crack (R-SFlex beams, Fig. 6-a), or due to the increase of the number of cracks towards the supports ( $R$-SDur beams, Fig. 6-b). The ultimate failure of each beam occurred when the extensive crack pattern reached the compressive zone of the glass web, precluding the mobilization of the binary between the GFRP reinforcement and the glass compression zone. The intrinsic scatter of glass strength was attested by the different cracking loads attained in the tests; 
Valarinho, L.; Sena-Cruz, J.; Correia, J.R.; Branco, F.A. (2017) "Numerical simulation of the flexural behaviour of composite glass-GFRP beams using smeared crack models." Composites Part B, 110: 336-350.

however, such scatter had only slight influence on the overall flexural behaviour of the composite beams, namely in the post-cracked stage.

Besides the crack pattern, the two adhesives provided different performance before and after glass breakage. Due to the low Young's modulus of SFlex adhesive, R-SFlex beams were unable to achieve the full level of interaction between glass and GFRP, which resulted in lower initial stiffness and cracking load; however, its higher energy redistribution capacity allowed $R$-SFlex beams to present significant post-cracking ductility levels (ratio between the displacement at the moment of the appearance of the first crack and the displacement at failure), although under residual post-cracking resistance. On the other hand, the $R$-SDur beams presented higher values of initial stiffness and cracking load and were able to recover the total initial strength during the post-cracking stage.

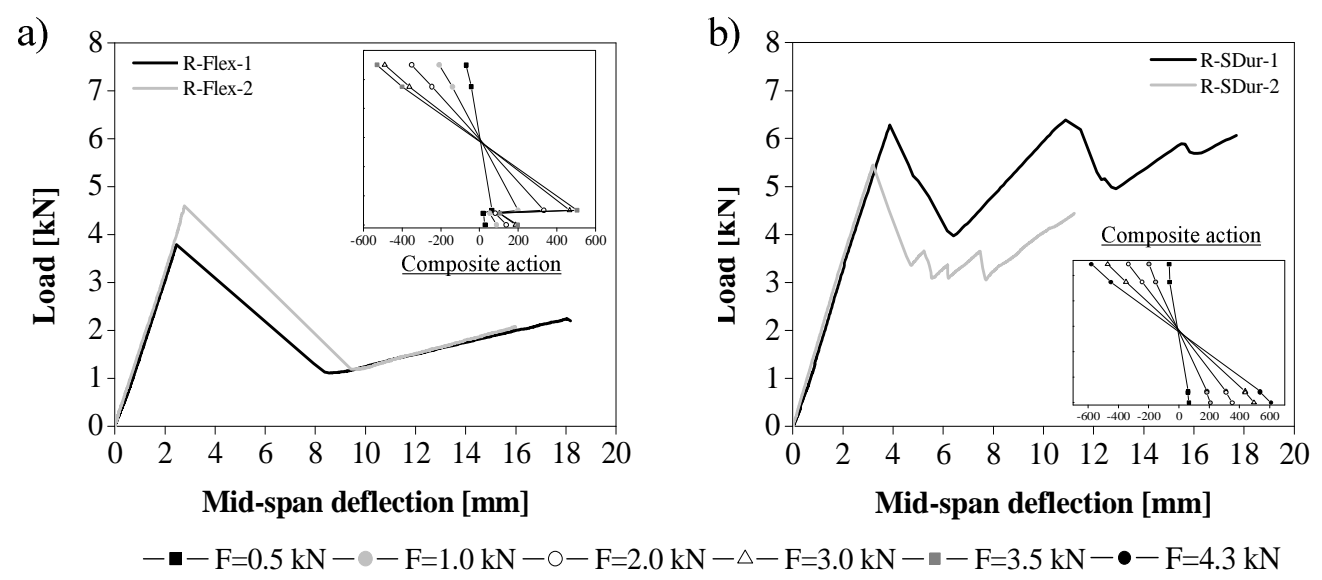

Fig. 5 - Load vs. mid-span deflection curves and composite action of (a) R-SFlex and (b) R-SDur beams.
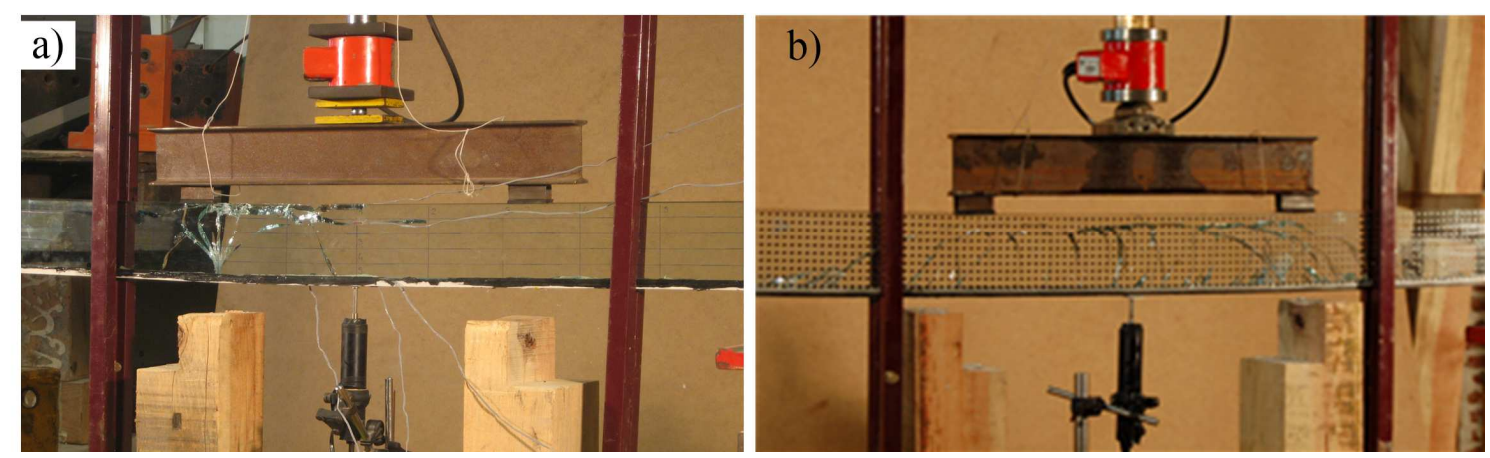

Fig. 6 - Experimental crack pattern of (a) R-SFlex and (b) R-SDur beams. 
Valarinho, L.; Sena-Cruz, J.; Correia, J.R.; Branco, F.A. (2017) "Numerical simulation of the flexural behaviour of composite glass-GFRP beams using smeared crack models." Composites Part B, 110: 336-350.

Table 2 summarizes the main results obtained from the flexural tests on the composite glass-GFRP beams in terms of initial stiffness (uncracked stage), cracking load, maximum load (only $R$-SDur beams attained loads equal to the cracking load), post-cracking strength (ratio between the maximum load at the cracked stage and the cracking load) and post-cracking ductility.

Table 2 - Summary of the 4-point bending tests on composite glass-GFRP beams.

\begin{tabular}{lcc}
\hline Geometry - Adhesive & R-SFlex & R-SDur \\
\hline Average test speed (prior to/after cracking) [mm/min] & $1.05 / 1.70$ & $1.52 / 1.85$ \\
Initial stiffness [kN/mm] & 1.44 & 1.67 \\
Cracking load [kN] & 3.70 & 5.87 \\
Maximum load [kN] & 3.70 & 5.92 \\
Post-cracking strength [\%] & 52 & 93 \\
Ductility index [\%] & 659 & 404 \\
\hline
\end{tabular}

\section{Description of the numerical models}

\subsection{Initial considerations}

The numerical models aimed at simulating the flexural responses of the composite glass-GFRP beams described above, namely the pre- and post-cracking behaviour of the beams made with the two different adhesives.

The first step of the simulations required the correct definition of the glass non-linear material characteristics according to the SCA. To describe the non-linear tensile softening behaviour of glass an extensive parametric study was developed in order to assess the influence of the following parameters (Table 3): (i) tensile strength of glass, $f_{g, t}$, (ii) mode-I fracture energy, $G_{f}$, (iii) crack band width, $h$, (iv) shape of the tension-softening diagram, and (v) type of shear retention factor law, $\beta$. For simplicity, at this stage the parametric studies on glass-GFRP composite beams were performed on models assuming perfect bond at the interfaces.

Table 3 - Numerical options tested for the description of the glass non-linear behaviour.

\begin{tabular}{ll}
\hline Parameter studied & Tested range \\
\hline Mode I fracture energy, $G_{f}[\mathrm{~N} / \mathrm{m}]$ & $3 ; 30 ; 188^{* \#} ; 300 ; 3000$ \\
Crack band width, $h[\mathrm{~mm}]$ & $\sqrt{A_{\text {element }}} * ; 1.0 ; 0.1$
\end{tabular}


Valarinho, L.; Sena-Cruz, J.; Correia, J.R.; Branco, F.A. (2017) "Numerical simulation of the flexural behaviour of composite glass-GFRP beams using smeared crack models." Composites Part B, 110: 336-350.

\begin{tabular}{|c|c|}
\hline \multirow{3}{*}{$\begin{array}{l}\text { Glass strength, } f_{g, t}[\mathrm{MPa}] \\
\text { Shape of tension-softening diagram } \\
\text { Shear retention factor, } \beta\end{array}$} & $45 ; 50 * ; 55$ \\
\hline & Linear*; Bilinear; Exponential \\
\hline & $1 \times 10^{-5} ; 1 \times 10^{-1} ; 0.99 ; \mathrm{p}=1 ; \mathrm{p}=2^{*} ; \mathrm{p}=3$ \\
\hline
\end{tabular}

The second step of the simulation focused on the numerical modelling of the adhesively bonded joints of the composite beams. For that three different models of the beams' joints were tested: (i) the Perfect Bond $(P B)$ model, where perfect bond between glass and GFRP was assumed, neglecting the physical existence of the adhesive; (ii) the Plane Stress Elements (PSE) model, in which the adhesives were explicitly simulated using plane stress elements together with the hypothesis of perfect bond at the glass/adhesive and adhesive/GFRP interfaces ${ }^{5}$; and (iii) the Interface Elements (IE) model, where interface elements were used to simulate the effects of both the adhesive and the interfaces (glass/adhesive and adhesive/GFRP). The parameters that define the mechanical properties of the joints in the last two models were obtained using two different approaches. On one hand, the joints of the PSE models were simulated using the information retrieved from the adhesives' characterization tests. On the other hand, the parameters that define the linear and non-linear constitutive laws of the bonded interfaces, namely the ones that define the shear behaviour of the interface elements for the two different adhesives, were parametrized through inverse FE analysis of the double-lap joints ( $c f$. section 4.2.1). Table 4 summarizes all the models developed as well as their assumptions and applicability.

Table 4 - Summary of the FE models developed for the composite beams adhesively bonded joints.

\begin{tabular}{lll}
\hline Beam model & Assumptions* $^{*}$ Applicability \\
\hline Perfect bond $(P B)$ & $\begin{array}{l}\text { No elements used to simulated the adhesive joint } \\
\text { Perfect bond between glass and GFRP is assumed }\end{array}$ & \multirow{2}{*}{ R-SDur } \\
\hline Plane stress elements (PSE) & $\begin{array}{l}\text { Joint simulated by plane stress adhesive elements } \\
\text { Perfect bond at all interfaces }\end{array}$ & R-SDur, R-SFlex \\
\hline Interface elements (IE) & $\begin{array}{l}\text { Joint simulated using interface elements } \\
\text { Coupled adhesive and interfaces simulation }\end{array}$ & \multirow{2}{*}{ R-SFlex, R-SDur } \\
\hline *Glass was always simulated as a non-linear material & \\
\hline
\end{tabular}

\footnotetext{
${ }^{5}$ The DL-SFlex specimens failure mode reported in the double-lap joint tests ( $c f$. Table 1) was neglected, thus the model does not account for adhesive failure modes.
} 
Valarinho, L.; Sena-Cruz, J.; Correia, J.R.; Branco, F.A. (2017) "Numerical simulation of the flexural behaviour of composite glass-GFRP beams using smeared crack models." Composites Part B, 110: 336-350.

\subsection{Geometry, boundary conditions and type of elements}

\subsubsection{Double-lap joints}

The double-lap joints were modelled as a plane stress problem. Due to their double symmetry, only $1 / 4$ of the double lap joint specimens was simulated. The geometry, mesh, boundary conditions and load configuration are shown in Fig. 7. Both glass and GFRP materials were simulated using 8-node Serendipity plane stress elements with $2 \times 2$ Gauss-Legendre integration scheme. The adhesive layer that connects the GFRP and glass was simulated by 6-node zero thickness interface elements with 3points Gauss-Lobatto integration rule. The thickness of the adhesive layer was reproduced by positioning both adherends at a distance of $2.0 \mathrm{~mm}$ with the interface elements in between.

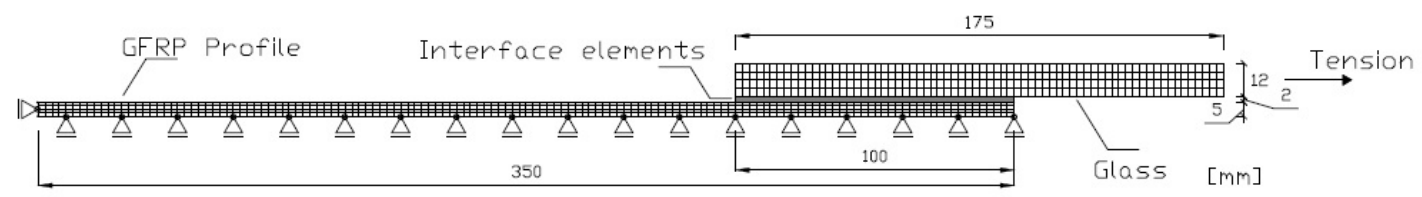

Fig. 7 - Mesh and boundary conditions of the double-lap joints numerical models.

\subsubsection{Composite beams}

The rectangular composite beams were numerically simulated taking into account symmetry considerations and considering their real geometry. Therefore, only half span of the composite beam was modelled. Both the glass pane and the GFRP reinforcement were modelled by means of 8-node Serendipity plane stress elements with $2 \times 2$ Gauss-Legendre integration scheme (plane stress analysis). For the adhesive joints the three different approaches mentioned above were studied. Fig. 8 depicts the geometrical differences of each approach, as well as the overall geometry of the numerical models of the composite beams, their boundary conditions, load configuration and mesh size adopted ${ }^{6}$. The depth of the adhesive joints of all models, simulated either with plane stress elements or with interface elements (6-node zero thickness interface elements ${ }^{7}$ with 3 points Gauss-Lobatto integration rule),

\footnotetext{
${ }^{6}$ A mesh sensitivity analysis was performed in preliminary studies developed with linear elastic materials; those studies showed that 8-node Serendipity elements with a mesh of $10 \times 10 \mathrm{~mm}^{2}$ give sufficiently accurate simulations. ${ }^{7}$ Constitutive laws presented in section 4.3.3.
} 
Valarinho, L.; Sena-Cruz, J.; Correia, J.R.; Branco, F.A. (2017) "Numerical simulation of the flexural behaviour of composite glass-GFRP beams using smeared crack models." Composites Part B, 110: 336-350.

was equal to the glass web thickness. The maximum number of elements was 975 on $P B$ models, 1200 on PSE models and 1050 on the IE models; in all cases, the mesh density was much lower than the ones adopted in $[13,25]$ for beams with comparable geometry and length.

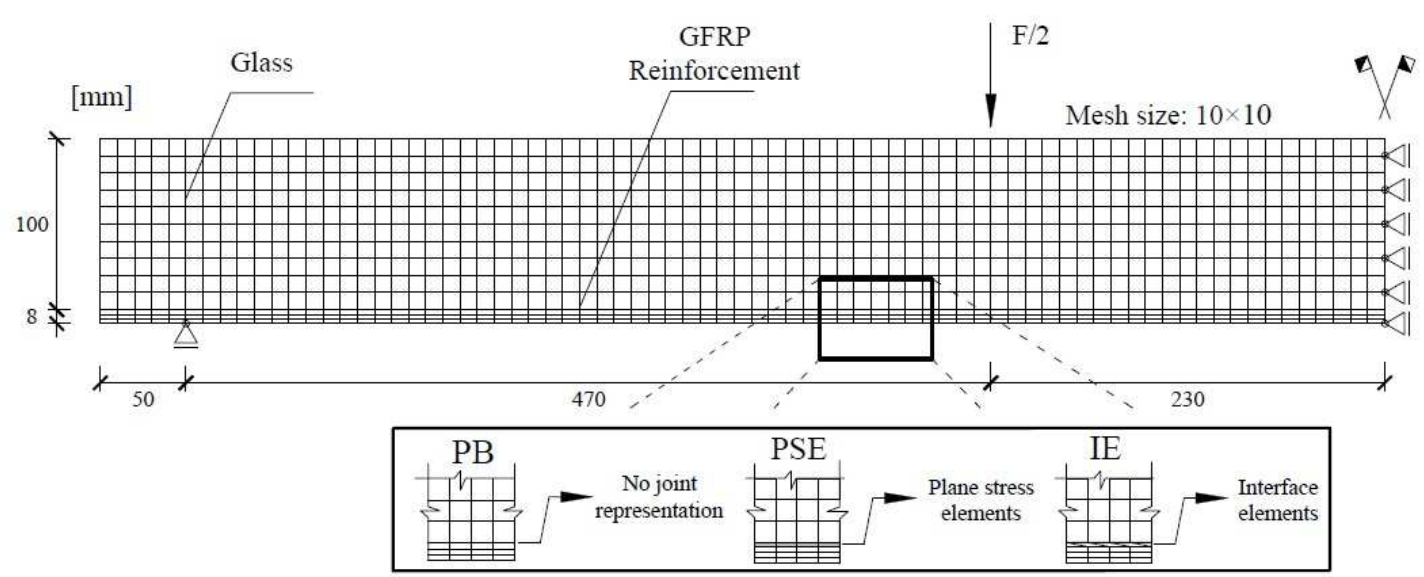

Fig. 8 - Mesh, boundary conditions and joint properties of the beams numerical models.

\subsection{Constitutive models of materials and interfaces}

The hybrid glass system comprises three different materials. In section 3.2 the main mechanical properties experimentally determined were presented. This section presents detailed information on how each material was numerically simulated, namely the constitutive models used to represent the fracture of glass, as well as all the joint properties and constitutive laws adopted to simulate the mechanical behaviour of beams bonded with different adhesives.

\subsubsection{Glass}

For simulating the linear elastic behaviour of glass, the recommendations of the Guideline for European Structural Design of Glass Components [26] were followed, for which annealed glass has a Young's modulus $\left(E_{g}\right)$ of approximately $70 \mathrm{GPa}$, a Poisson's ratio of 0.23 and a tensile strength $\left(f_{g, t}\right)$ ranging from 30 to $80 \mathrm{MPa}^{8}$.

\footnotetext{
${ }^{8} f_{g, t}$ is a mechanical property of glass known to be dependent on a variety of factors, such as size of existing micro cracks, surface side, panel size, stress distribution or load duration. Depending on these factors and under a relatively low stress rate, crack growth develops on small existing flaws, increasing their size and ultimately
} 
Valarinho, L.; Sena-Cruz, J.; Correia, J.R.; Branco, F.A. (2017) "Numerical simulation of the flexural behaviour of composite glass-GFRP beams using smeared crack models." Composites Part B, 110: 336-350.

In the models of the double-lap joints ( $c f$. section 4.2.1), glass was simulated as linear elastic, for both compression and tension, using the aforementioned properties. No failure criterion was considered. For the composite glass-GFRP beam models, glass was simulated as linear elastic in compression and in tension prior to cracking; after cracking, non-linear behaviour was considered with cracking being simulated according to the SCA (non-linear fracture mechanics). Furthermore, an extensive numerical assessment, summarized in Table 3, was performed in order to calibrate five important parameters required for the definition of the above non-linear material model of glass. In the next paragraphs a detailed description of the assumptions made for each parameter is provided. The following nomenclature (5 labels) was considered: " $G_{f}-h-f_{g, t}$ - shape of tension-softening diagram - $\beta$ ”. A single parameter was changed at a time (all the others remained with its default value), with the exception of models with $G_{f}$ lower than $188 \mathrm{~N} / \mathrm{m}^{9}$, where $h$ was also changed, in order to achieve low $G_{f}$ values (ahead in this section). The default properties of the glass non-linear material (hereafter referred to as Standard Non-linear Material Model for Glass or SNLMMG) are highlighted in Table 3. The calibrated glass non-linear model was then used on the PSE and IE models.

As a result of the two main assumptions made in the SCA (mentioned in Section 2), the crack normal stress is determined by a tension-strain constitutive law (usually named tension-softening diagram) defined by the $f_{g, t}, G_{f}$ and $h$. The first two parameters (as well as the shape of the tension-softening diagram) are considered material properties and the last one is inherent to the SCA. Traditionally, for computational reasons, two additional assumptions are made in the SCA: (i) computational instabilities and convergence issues (e.g. snap-back instabilities) should be avoided, and (ii) mesh objectivity should be preferably assured. The snap-back instability is avoided by ensuring a maximum value of $h$ (Eq. (1-a)), which is dependent of the maximum unidimensional slope $(b)$ of the softening branch in the tension-softening diagram, $G_{f}, f_{g, t}$ and $E_{g}[8,16]$. The mesh objectivity is ensured by

causing the collapse of glass elements. Some studies indicate that strength may vary from $30 \mathrm{MPa}$ to $80 \mathrm{MPa}$ due to those factors $[32,33]$.

${ }^{9}$ Corresponding to the minimum $G_{f}$ to avoid snap-back instabilities, as discussed in this section. 
Valarinho, L.; Sena-Cruz, J.; Correia, J.R.; Branco, F.A. (2017) "Numerical simulation of the flexural behaviour of composite glass-GFRP beams using smeared crack models." Composites Part B, 110: 336-350.

simply assuming a relationship between $h$ and mesh size (e.g., $h$ equal to the square rote of the finite elements' area [8]). In summary, the classical numerical approach to guarantee stability and convergence in smeared crack models involves controlling the $h$ (and not any of the other parameters, which are assumed to be constant material properties), which is mesh-dependent. Therefore, according to Eq. (1-a), there is a maximum value of $h$ that can be used in order to simulate a specific material or, in other words, the FE mesh size is directly dependent on the simulated material and its properties. In brittle materials like glass, which presents very low $G_{f}$, that assumption requires the use of highly discretised models, with all the disadvantages involved.

$$
h \leq \frac{G_{f} \cdot E_{g}}{f_{g, t}^{2} \cdot b} \quad G_{f, \min } \geq \frac{f_{g, t}^{2} \cdot h \cdot b}{E_{g}}
$$

The above mentioned numerical approach was originally developed for concrete in softening. Since its applicability to glass fracture was not yet comprehensively assessed, in this paper the influence of all parameters in Eq. (1) (with the exception of $E_{g}$ ) was investigated considering the following two criteria: (i) the mesh size was kept as $10 \times 10 \mathrm{~mm}^{2}$, and (ii) the snap-back instability was avoided by assuming a $G_{f}$ value higher than the minimum required by Eq. (1-b), which results from a direct manipulation of Eq. (1-a). The main objective was to assess the effects of using models with less discretized meshes and, consequently, higher $G_{f}$ values, which, although not fully accurately representing the fracture properties of glass, would be much less time consuming and would face much less convergence issues

The influence of $G_{f}$ on the $P B$ model was assessed by testing a wide range of $G_{f}$ from $3 \mathrm{~N} / \mathrm{m}$ (the reference value reported in the literature) to $3000 \mathrm{~N} / \mathrm{m}$ (Table 3). The tested values were lower, higher and equal to the minimum energy required when assuming a $10 \times 10 \mathrm{~mm}^{2}$ mesh size and $h$ equal to the square root of the FEs' $\operatorname{area}^{10}$.

\footnotetext{
${ }^{10}$ In true, the value of $G_{f}$ considered was $5 \%$ higher than the value yielded by Eq. (1-b) due to convergence issues. Models with a mesh of $10 \times 10 \mathrm{~mm}^{2}$ and different parameter combinations have repeatedly shown convergence issues after the appearance of the first crack or in a premature crack stage. Therefore, the $G_{f, \min }$ was slightly increased from $178.57 \mathrm{~N} / \mathrm{m}$ to $188.04 \mathrm{~N} / \mathrm{m}$.
} 
Valarinho, L.; Sena-Cruz, J.; Correia, J.R.; Branco, F.A. (2017) "Numerical simulation of the flexural behaviour of composite glass-GFRP beams using smeared crack models." Composites Part B, 110: 336-350.

The complete range of tested $G_{f}$ was defined by assuming two different hypotheses for $h$ : (i) for $G_{f}>$ $G_{f, \text { min }}$, mesh objectivity was kept, thus $h=\sqrt{A_{\text {element }}}=10 \mathrm{~mm}$; (ii) for $G_{f}<G_{f, \min }$, the mesh objectivity was neglected and $h$ was equal to $1.0 \mathrm{~mm}$ and $0.1 \mathrm{~mm}$, resulting in $G_{f}$ values of $30 \mathrm{~N} / \mathrm{m}$ and $3 \mathrm{~N} / \mathrm{m}$, respectively. The analysis of the effects of $h$ on the numerical response of the composite beams was included in the discussion about the influence of fracture energy (i.e. section 5.2.1.1), since the main goal of changing $h$ was to achieve the glass fracture energy mentioned in the literature.

In this study, the following three different $f_{g, t}$ values were considered: $45 \mathrm{MPa}, 50 \mathrm{MPa}$ and $55 \mathrm{MPa}$. The main objective was to assess the possible influence of the cracking load (as experimentally observed) on the behaviour of the numerical models. Since the $G_{f, \min }$ of the numerical models is dependent on the material's tensile strength (Eq. (1-b)), two approaches were adopted: (i) $G_{f}$ was assumed equal to the minimum required for each $f_{g, t}$ considered (changing from model to model), or (ii) $G_{f}$ was considered constant and equal to the minimum required by the model with the highest $G_{f, \text { min }}\left(\right.$ model “ $G_{f, \min }-\sqrt{A_{\text {element }}}-55-$ Linear -2 ").

The non-linear material behaviour of glass was analysed using three different tension-softening diagrams (Fig. 9): (i) the Linear diagram that corresponds to a linear softening branch, which minimizes $G_{f}(b=0.5)$; (ii) the Bilinear diagram that aims at representing a higher energy loss in the beginning of the softening branch, which is a possible feature of brittle materials with a semi-stable fracture [9] ( $b=0.9$ ); and (iii) the Cornelissen diagram [27], a negative exponential softening law that presents a smooth energy degradation, providing advantages in terms of convergence $(b \approx 1.37)$. The last two diagrams have the disadvantage of presenting a higher maximum slope, which also affects the $G_{f, \min }$ value needed for the simulations (Eq. (1-b)). Therefore, the models required higher $G_{f}$ values, more precisely, the models with the Bilinear and Cornelissien diagram were simulated with a fracture energy value of $321 \mathrm{~N} / \mathrm{m}$ and $487 \mathrm{~N} / \mathrm{m}$, respectively. 
Valarinho, L.; Sena-Cruz, J.; Correia, J.R.; Branco, F.A. (2017) "Numerical simulation of the flexural behaviour of composite glass-GFRP beams using smeared crack models." Composites Part B, 110: 336-350.
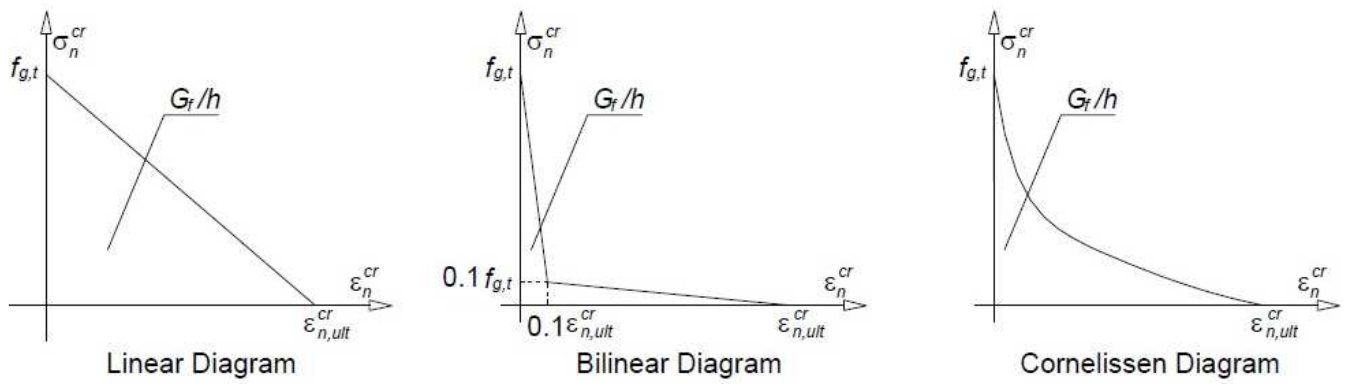

Fig. 9 - Tension-softening diagrams simulated for glass non-linear material.

The non-linear material model used allows the evaluation of the shear retention factor in two distinct ways [28]: (i) a constant value, and (ii) a non-constant value defined by Eq. (2),

$$
\beta=\left(1-\frac{\varepsilon_{n}^{c r}}{\varepsilon_{n, u l t}^{c r}}\right)^{p}
$$

where $p$ is a parameter that can assume the values of 1,2 or 3 , and $\varepsilon_{n}^{c r}$ and $\varepsilon_{n, u l t}^{c r}$ are the crack normal strain and the ultimate crack normal strain, respectively. The $P B$ models of the beams were tested for constant values of $\beta=0.00001, \beta=0.01, \beta=0.1, \beta=0.99$ and all the possible power laws available $(\mathrm{p}=1,2,3)$.

In what concerns crack triggering and initiation, in the multi-fixed smeared crack model used, a new crack is initiated when the maximum principal stress in a specific integration point exceeds the uniaxial tensile strength and the angle between the direction of the existing cracks and the direction of the maximum principal stress exceeds the value of a predefined threshold angle [16]. In this study, the threshold angle was assumed constant and equal to $30^{\circ}$ and a maximum of 2 cracks per integration point was allowed to arise.

\subsubsection{GFRP}

In the models of the double-lap joints and the glass-GFRP composite beams, GFRP was modelled as linear elastic, for both tension and compression, according to the mechanical properties experimentally determined and presented in section 3.2.

\subsubsection{Adhesives and interfaces}

$P B$ models, i.e. models that assume perfect bond at the interfaces, are only valid for connections that 
Valarinho, L.; Sena-Cruz, J.; Correia, J.R.; Branco, F.A. (2017) "Numerical simulation of the flexural behaviour of composite glass-GFRP beams using smeared crack models." Composites Part B, 110: 336-350.

present high levels of interaction. Therefore, in this study, it was assumed that this hypothesis was a good approximation for joints bonded with the SDur adhesive (cf. Fig. 5-b). For beams that presented low levels of interaction ( $R$-SFlex beams) this approximation could not be accounted for and different models were tested.

In the PSE models the adhesives were modelled as linear elastic. The Young's modulus and Poisson's ratio of each adhesive were defined based on experiments ( $c f$. section 3.2). Despite its higher simplicity, these models did not account for any slippage at the interfaces nor for any potential influence of the adhesives' viscoelasticity. This explains why they were not able to accurately represent the interface behaviour reported on the DL-SFlex experiments, where debonding at the interfaces took place.

On the other hand, when using interface elements (whose constitutive laws can be linear or non-linear with/without softening), both the mechanical properties of the adhesive and the adhesion characteristics at the interfaces can be considered. In the $I E$ models, two different constitutive laws were used in the interface elements according to the adhesive simulated with the main purpose of replicating the initial experimental stiffness of the double-lap joints. In the IE-SDur models (developed to simulate the $R$-SDur beams) a linear elastic law characterized by the normal and tangential stiffnesses ( $K_{n}$ and $K_{t}$, respectively) was simulated. In the IE-SFlex models (for the $R$-SFlex adhesive), a non-linear bond stress-slip relation was adopted, defined by the linear elastic normal stiffness $K_{n}$ and by Eq. (3), where $\tau_{\mathrm{m}}$ and $\mathrm{s}_{\mathrm{m}}$ are, respectively, the maximum shear stress and the corresponding maximum slip, and $\alpha$ and $\alpha$ ' are the parameters that define the shape of the pre- and post-peak curves, respectively [16]:

$$
\tau(s)= \begin{cases}\tau_{m}\left(\frac{s}{s_{m}}\right)^{\alpha} & \text { if } s \leq s_{m} \\ \tau_{m}\left(\frac{s}{s_{m}}\right)^{-\alpha \prime} & \text { if } s>s_{m}\end{cases}
$$

$K_{n}$ could not be calibrated, neither with the data retrieved from the shear tests nor with the data from the beams' flexural tests. Therefore, based on Sena-Cruz [16], $K_{n}$ was taken as $10^{6} \mathrm{kN} / \mathrm{m}^{3}$ to avoid 
Valarinho, L.; Sena-Cruz, J.; Correia, J.R.; Branco, F.A. (2017) "Numerical simulation of the flexural behaviour of composite glass-GFRP beams using smeared crack models." Composites Part B, 110: 336-350.

any influence on the shear behaviour of the interface elements. Table 5 presents the properties of the interface elements used to model each type of adhesively bonded specimens.

Table 5 - Properties of the interface elements considered for the two adhesives.

\begin{tabular}{lrrccc}
\hline Adhesive & $\boldsymbol{K}_{\boldsymbol{n}}\left[\mathbf{N} / \mathbf{m}^{3}\right]$ & $\boldsymbol{K}_{\boldsymbol{t}}\left[\mathbf{N} / \mathbf{m}^{\mathbf{3}}\right]$ & $\boldsymbol{s}_{\boldsymbol{m}}[\mathbf{m m}]$ & $\boldsymbol{\tau}_{\boldsymbol{m}}[\mathbf{M P a}]$ & $\boldsymbol{\alpha}[-]$ \\
\hline Sikaflex 265 & $10^{6}$ & N.A. & 4.20 & 1.70 & 0.90 \\
Sikadur31-cf & $10^{6}$ & 200 & N.A. & N.A. & N.A. \\
\hline *N.A. = not applicable & & & & &
\end{tabular}

\subsection{Type of analysis}

In the models of the double-lap joints, load was applied under displacement control at the end of the glass adherend. Two different failure criteria were set to control the numerical simulations: (i) for the SFlex adhesive the simulation was stopped when the maximum experimental displacement was attained ${ }^{11}$, whereas (ii) for the SDur adhesives simulations were performed until the stress in the glass adherends reached the $30 \mathrm{MPa}$ in pure tension (the maximum axial stress that was estimated to have occurred in the experiments).

In the beam tests, load was applied at one single point at the top edge of the glass pane, according to the experimental setup, and the numerical analysis was also undertaken under displacement control. The analysis was stopped when the maximum experimental displacement was attained (R-SFlex models) or when the initial strength was recovered ( $P B$ and $R$-SDur models).

\section{Results and discussion}

\subsection{Double-lap joints}

The load vs. relative displacement curves obtained from the numerical models are plotted and compared with the experimental data in Fig. 3 ( $c f$. section 3.3). It can be seen that, even for the $D L$ SFlex specimens, whose behaviour was slightly non-linear, the constitutive models adopted

\footnotetext{
${ }^{11}$ Despite the visual reports of an adhesive failure of the DL-SFlex joints, the debonding was only observed on a slight branch of the joint' load $v s$. relative displacement curves. The (double) redundancy of the specimens as well as the test setup and test measurement equipment did not allow to fully record the debonding phase. Therefore, debonding was not included in the numerical models of the double-lap joints.
} 
Valarinho, L.; Sena-Cruz, J.; Correia, J.R.; Branco, F.A. (2017) "Numerical simulation of the flexural behaviour of composite glass-GFRP beams using smeared crack models." Composites Part B, 110: 336-350.

reproduced accurately the initial slope of the experiments. Moreover, using interface elements with higher tangential stiffness led to a steeper initial distribution of axial strains. In opposition, a lower tangential stiffness caused a more linear distribution of axial strains along the overlap length.

Fig. 4 shows the numerical results in terms of axial strains along the overlap length of the specimens and the respective comparison with the experimental results. As for the load $v s$. relative displacement curves, in spite of the relatively high scatter of experimental data, a general good agreement was obtained between measured strains and numerical results, providing further validation to the $\mathrm{FE}$ models and, in particular, to the parameters used to simulate the constitutive relations of the bonded interfaces.

\subsection{Composite beams}

\subsubsection{Effect of non-linear glass material options}

\subsubsection{Fracture energy}

Fig. 10 compares the experimental load $v s$. mid-span deflection responses to numerical curves obtained considering different $G_{f}$ values. The results show that all models properly reproduced the overall experimental behaviour of the glass composite beams, with the exception of the model with $G_{f}=3000$ $\mathrm{N} / \mathrm{m}$. The overall numerical behaviour was similar to the experimental observations, presenting an initial linear response (initial flexural stiffness of $1.57 \mathrm{kN} / \mathrm{mm}$ ) followed by a post-cracking stage with progressive loss of stiffness. 


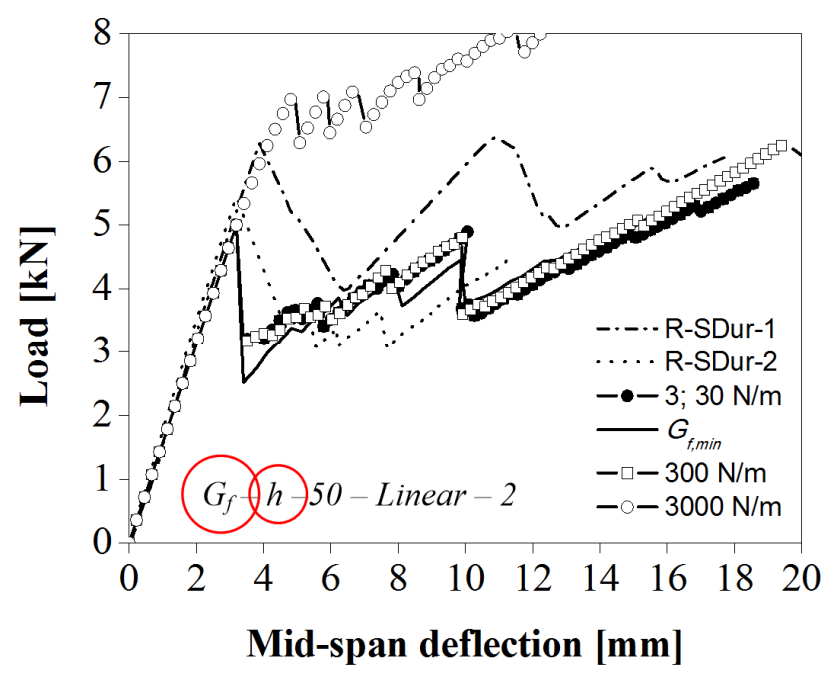

Fig. 10 - Effect of $G_{f}$ on the load $v s$. mid-span displacement curves of $R$-SDur beams.

With the exception of model " $3000-\sqrt{A_{\text {element }}}-50$ - Linear - 2", all the numerical models predicted the crack load initiation (equal to $5.0 \mathrm{kN}$ ) for the correspondent experimental load. After this point, as in the experiments, a sudden load decay was observed. However, a large difference can be observed between the numerical and experimental deflections at this specific point. That difference is attributed to the fact that the data acquisition speed $(\approx 5 \mathrm{~Hz})$ was not fast enough to capture such sudden load drop in the experiments. The post-cracking stage was very similar between models and minor differences were found. In true, if the displacement path would be kept, all models (with the exception of model with $G_{f}=3000 \mathrm{~N} / \mathrm{m}$ ) would yield the same post-cracking response. This result seems to indicate that adding GFRP reinforcement to glass beams allows using a relatively wide range of $G_{f}$ values ( 3 to $300 \mathrm{~N} / \mathrm{m}$ ), considerably higher than the reference value reported in the literature, with no significant loss of precision. Fig. 11 presents the effect of $G_{f}$ on the crack pattern of the beams obtained for two different deflection values $^{12}$. As for the flexural behaviour, all models showed an equivalent behaviour, with an overall good agreement with the corresponding experimental observations ( $c f$. Fig. 6-b). In addition, in all models the oblique cracks developing at the GFRP vicinity along the shear span could be perfectly

\footnotetext{
${ }^{12}$ The behaviour of the model with $G_{f}=3000 \mathrm{~N} / \mathrm{m}$ was not considered in this comparison due to the poor compliance with the experimental load $v s$. deflection results.
} 
Valarinho, L.; Sena-Cruz, J.; Correia, J.R.; Branco, F.A. (2017) "Numerical simulation of the flexural behaviour of composite glass-GFRP beams using smeared crack models." Composites Part B, 110: 336-350.

traced in the experimental prototype. During the post-cracking stage, the existing cracks are always "fully opened" (cracks in purple), i.e. mode I fracture energy is fully exhausted in those cracks.

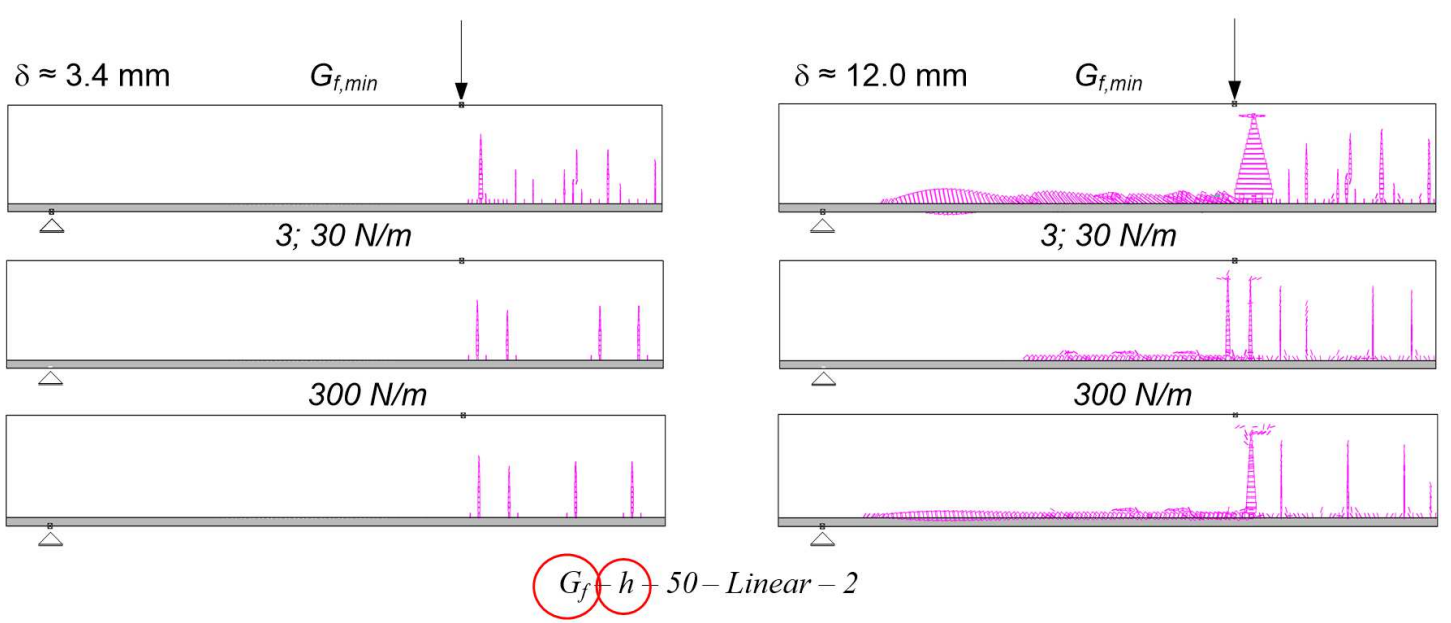

Fig. 11 - Effect of $G_{f}$ on the composite beam's crack pattern. Crack legend: fully-open (purple).

Finally, all models were able to recapture the initial strength, which was set as the stopping criterion in the models. At this point, no substantial differences were detected between the different numerical models in terms of deformed shapes, stress distributions and crack patterns (Fig. 12). This result, once more, sustains that during the post-cracking stage the GFRP reinforcement was the main component governing the beam's behaviour, and hence a fully accurate definition of $G_{f}$ was not a critical factor.

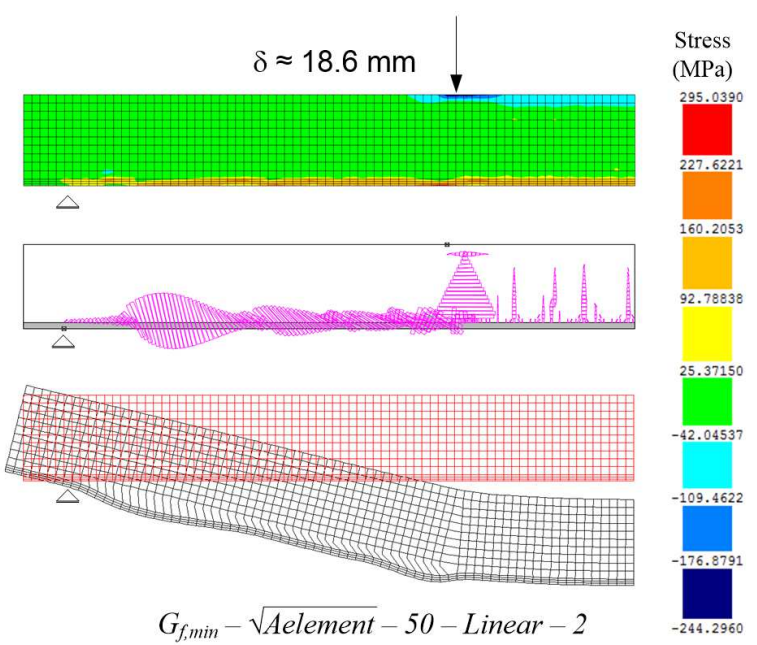

Fig. 12 - Numerical results of model " $G_{f, \min }-\sqrt{A_{\text {element }}}-50$ - Linear - 2" in terms of (a) stress distribution, (b) crack pattern and (c) deformed shape. 
Valarinho, L.; Sena-Cruz, J.; Correia, J.R.; Branco, F.A. (2017) "Numerical simulation of the flexural behaviour of composite glass-GFRP beams using smeared crack models." Composites Part B, 110: 336-350.

Crack legend: closed (green), and fully-open (purple).

\subsubsection{Tensile strength}

Fig. 13 presents a comparison between the experimental and numerical load vs. mid-span deflection curves of $R$-SDur beams, by considering $f_{g, t}$ of $45 \mathrm{MPa}, 50 \mathrm{MPa}$ and $55 \mathrm{MPa}$. It can be seen that changing the $f_{g, t}$ did not affect the overall qualitative behaviour of the beams for both modelling approaches considered ${ }^{13}$ ( $c f$. section 4.3.1). Aside from the expected differences on the cracking loads and initial load drop, all models were able to keep their integrity and restore the beams' initial strength. In addition, the post-cracking process, the progressive loss of stiffness and the residual strength were similar among the different beams.

In what concerns crack pattern, minor differences were found between the models with $f_{g, t}=45 \mathrm{MPa}$ and $f_{g, t}=50 \mathrm{MPa}$ (Fig. 14). However, the model with $f_{g, t}=55 \mathrm{MPa}$ was unable to simulate multiple cracks with high vertical development and, for a high value of displacement, a significant reduction of the number of shear cracks was visible. This is in line with the general behaviour that would be expected from a material with a higher tensile strength.
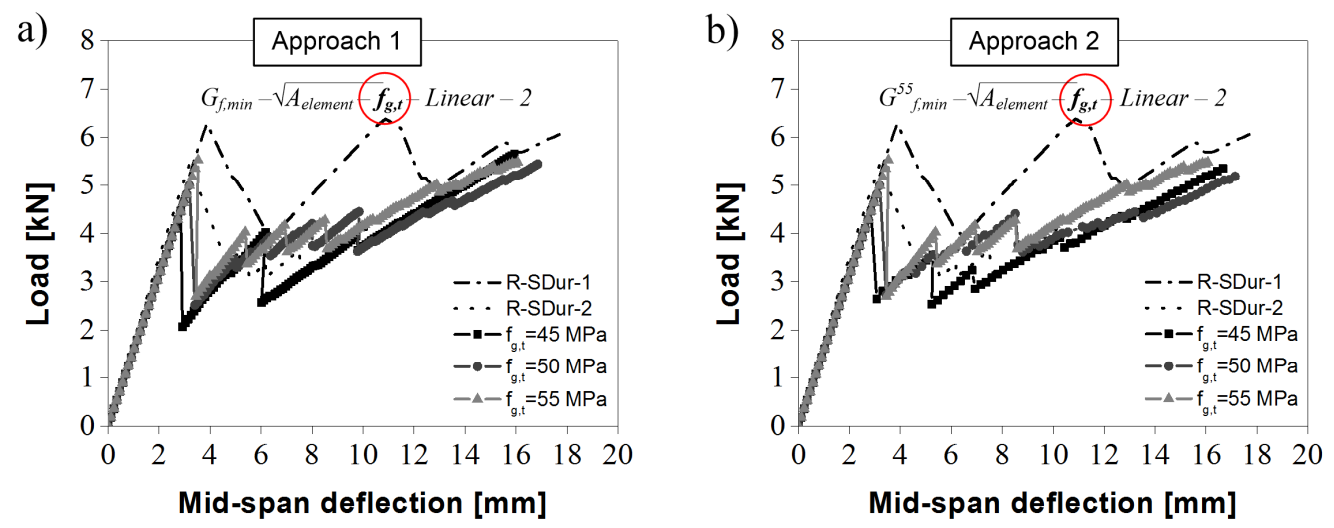

Fig. 13 - Effect of $f_{g, t}$ on the load vs. mid-span deflection curves, considering (a) approach 1, and (b) approach 2.

\footnotetext{
${ }^{13}$ Approach 1 assumes $G_{f}=G_{f, \min }$ of each model; Approach 2 assumes an unique $G_{f}$ in all models, equivalent to the $G_{f, \min }$ of model with $f_{g t}=55 \mathrm{MPa}$.
} 


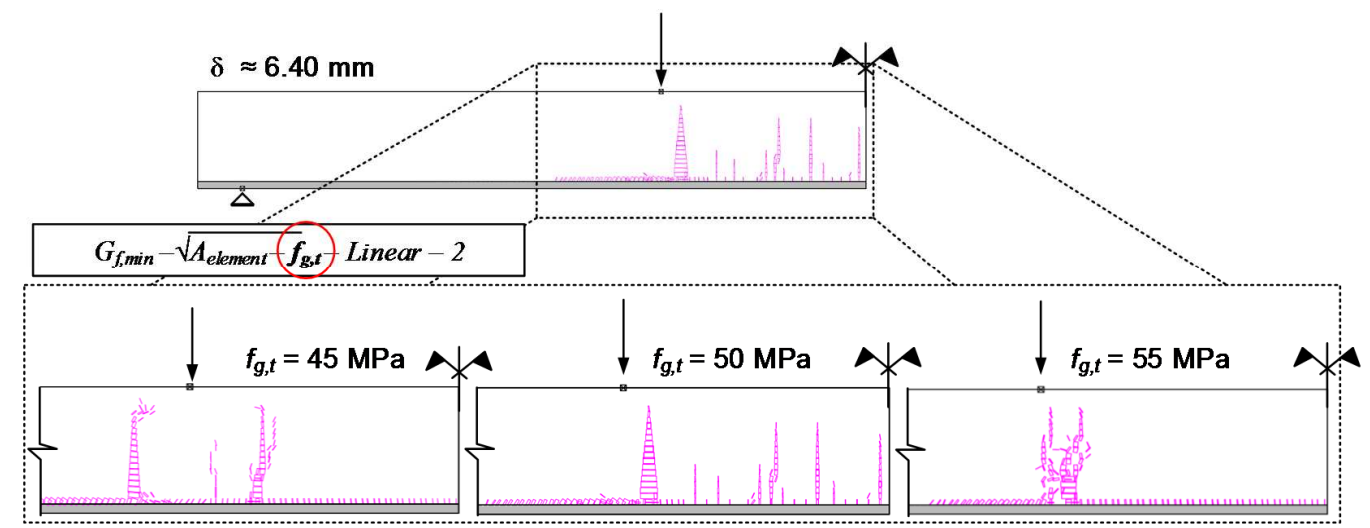

Fig. 14 - Effect of $f_{g, t}$ on the crack pattern for, from left to right, $f_{g, t}=45 \mathrm{MPa}, 50 \mathrm{MPa}$ and $55 \mathrm{MPa}$ (approach 1). Crack legend: fully-open (purple).

\subsubsection{Tension-softening diagram}

Fig. 15 shows the comparison between the experimental flexural behaviour of the $R$-SDur beams and the numerical behaviour obtained for the three different tension-softening diagrams simulated. It can be seen that the bilinear shape is the one that best simulates the observed experimental behaviour. The other two constitutive laws clearly overestimated the post-cracking flexural performance and did not exhibit a progressive loss of stiffness after the initial load drop: for a displacement of $10 \mathrm{~mm}$, the residual strength in those models was higher than the initial strength and around $42 \%$ higher than the experimental residual strength measured in $R$-SDur-2 beam specimen. These differences can also be observed in the crack pattern. Indeed, apart from the Bilinear diagram, none of the other two models tested was able to replicate shear cracks towards the supports, thus being unable to present a progressive loss of stiffness (Fig. 16). Although higher fracture energies had to be used with Bilinear and Cornelissien diagrams (respectively 1.7 and 2.6 times higher compared to the Linear one), the differences highlighted above are attributed essentially to the change of the shape of the different tension-softening diagram; indeed, for the Linear diagram, no significant changes in the numerical results were obtained when the fracture energy was increased up to 2.6 times the default value. 
Valarinho, L.; Sena-Cruz, J.; Correia, J.R.; Branco, F.A. (2017) "Numerical simulation of the flexural behaviour of composite glass-GFRP beams using smeared crack models." Composites Part B, 110: 336-350.

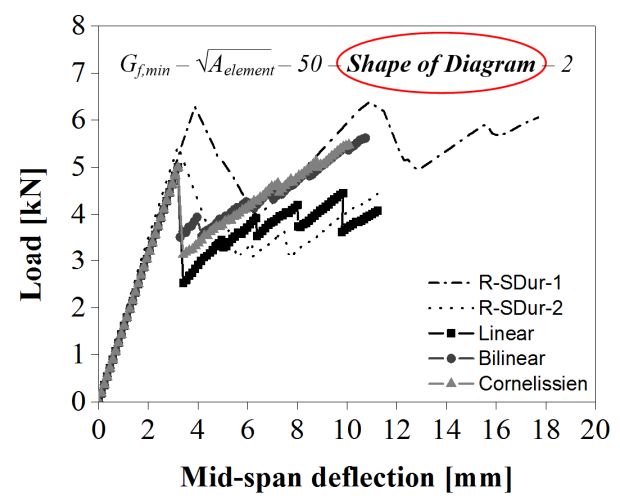

Fig. 15 - Effect of the tension-softening diagram shape on the load vs. mid-span deflection curves.

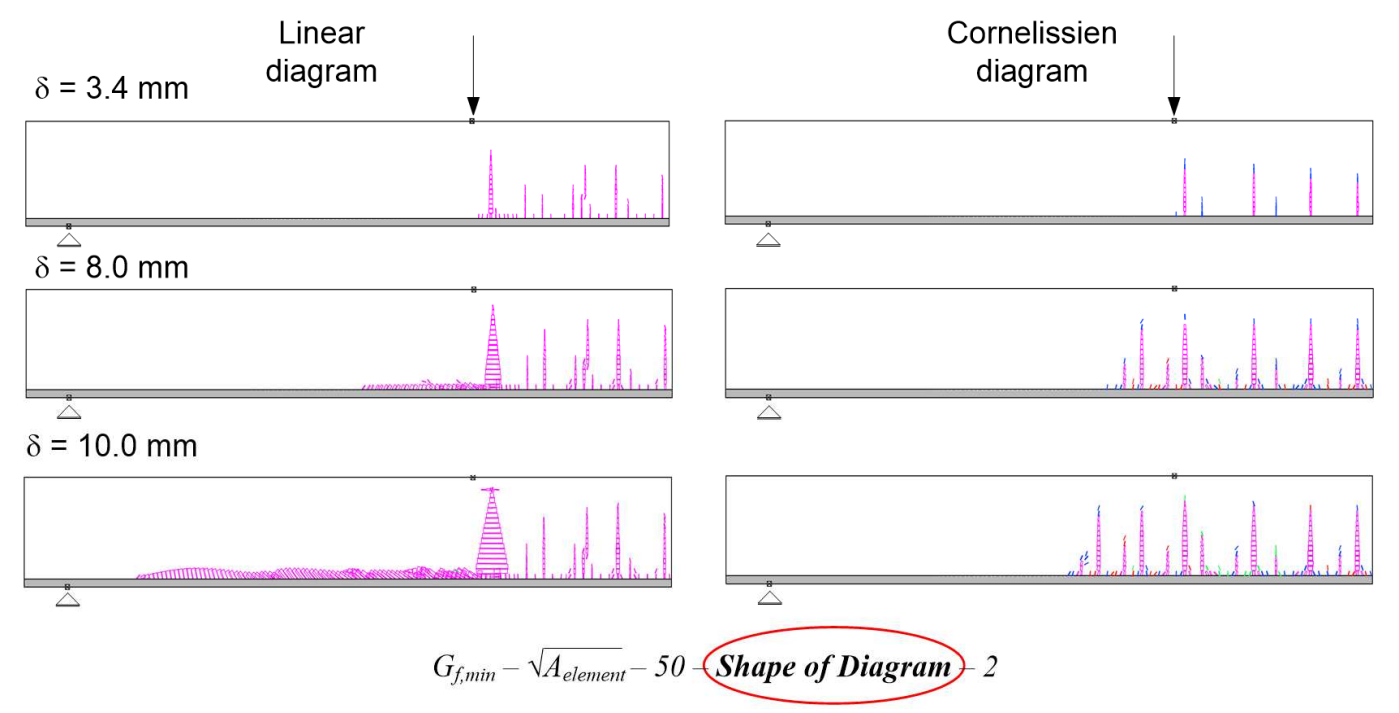

Fig. 16 - Effect of the tension-softening diagram shape on the crack pattern. Crack legend: opening (blue), closed (green), reopening (red) and fully-open (purple).

The reported differences may be related with the expected fracture behaviour of glass, which is closer to the Linear (brittle materials with semi-stable fractures) diagram than to the Bilinear or Cornelissien. The first diagram is the only one capable of rapidly exhausting the total low fracture energy of glass, presenting a low ultimate crack normal strain, which is a central criterion for simulating highly quasi-brittle materials, even if featuring a semi-stable fracture. The other two diagrams seem to have the disadvantage of retaining normal stresses for higher crack normal strains, not accurately representing the physical behaviour of glass. 
Valarinho, L.; Sena-Cruz, J.; Correia, J.R.; Branco, F.A. (2017) "Numerical simulation of the flexural behaviour of composite glass-GFRP beams using smeared crack models." Composites Part B, 110: 336-350.

\subsubsection{Shear retention factor}

Fig. 17 shows the influence of the shear retention factor on the numerical flexural response of the glass-GFRP composite beams. For low constant values of $\beta(<0.00001)$, the flexural behaviour presented good agreement with the experimental data, whereas for high constant values of $\beta$ the numerical models overestimated the residual strength. This result, together with the fact that during glass propagation most of the cracks are "fully-open", shows that glass cracks are either characterized by low values of $\beta$ or by high shear stiffness degradation once the $f_{g, t}$ is attained. Therefore, high constant values of $\beta$ do not correctly simulate the experiments and, conversely, low constant values seem to be a good approximation. Models with non-constant $\beta$ values, i.e. dependent on the current and ultimate crack normal strains, predicted the overall experimental response with fairly good accuracy, since they replicated high initial shear degradation. Minimum differences were found between the model with $\beta=0.00001$ or power law degradations using $p=1,2$ and 3 . These results are in agreement with the study of Bedon and Louter [13].
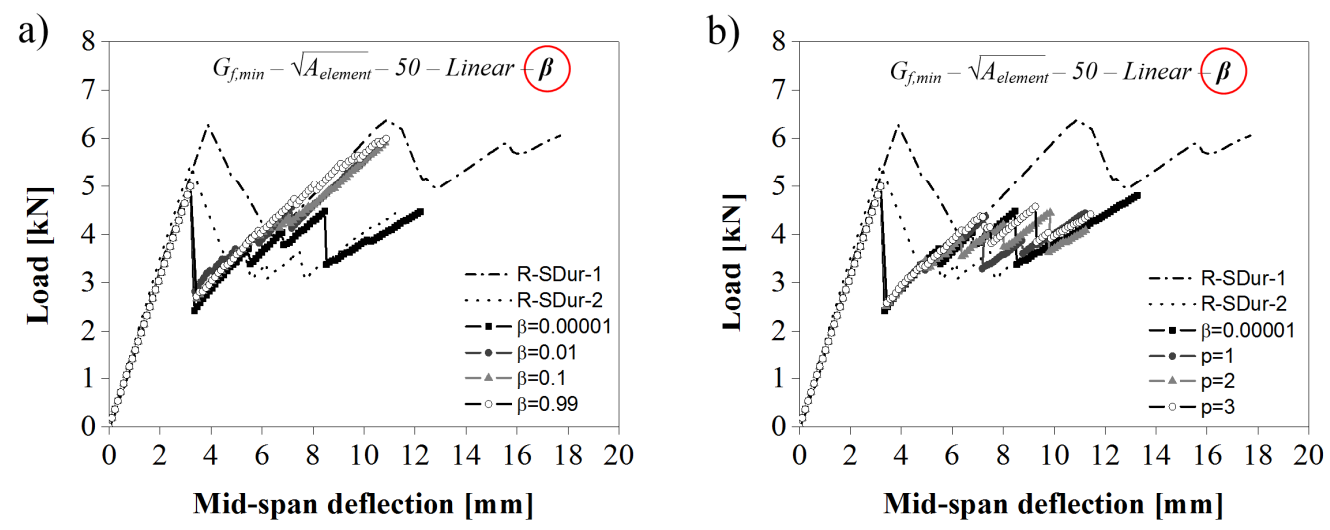

Fig. 17 - Effect of (a) constant and (b) variable $\beta$ on the load vs. mid-span deflection.

Similar conclusions can be drawn when analysing the crack pattern (Fig. 18), i.e. low constant values of $\beta$ yielded crack patterns with shear cracks as well as horizontal cracks on the upper part of the crosssection (tensile area), whereas for higher values of $\beta$ these two types of cracks were not yielded, despite a noticeable development of vertical cracks towards the supports. The best correlations were obtained 
Valarinho, L.; Sena-Cruz, J.; Correia, J.R.; Branco, F.A. (2017) "Numerical simulation of the flexural behaviour of composite glass-GFRP beams using smeared crack models." Composites Part B, 110: 336-350.

using a non-constant value of $\beta$, namely by taking $p=2$ ( $c f$. Fig. 14 and $f_{g t}=50 \mathrm{MPa}$ ).

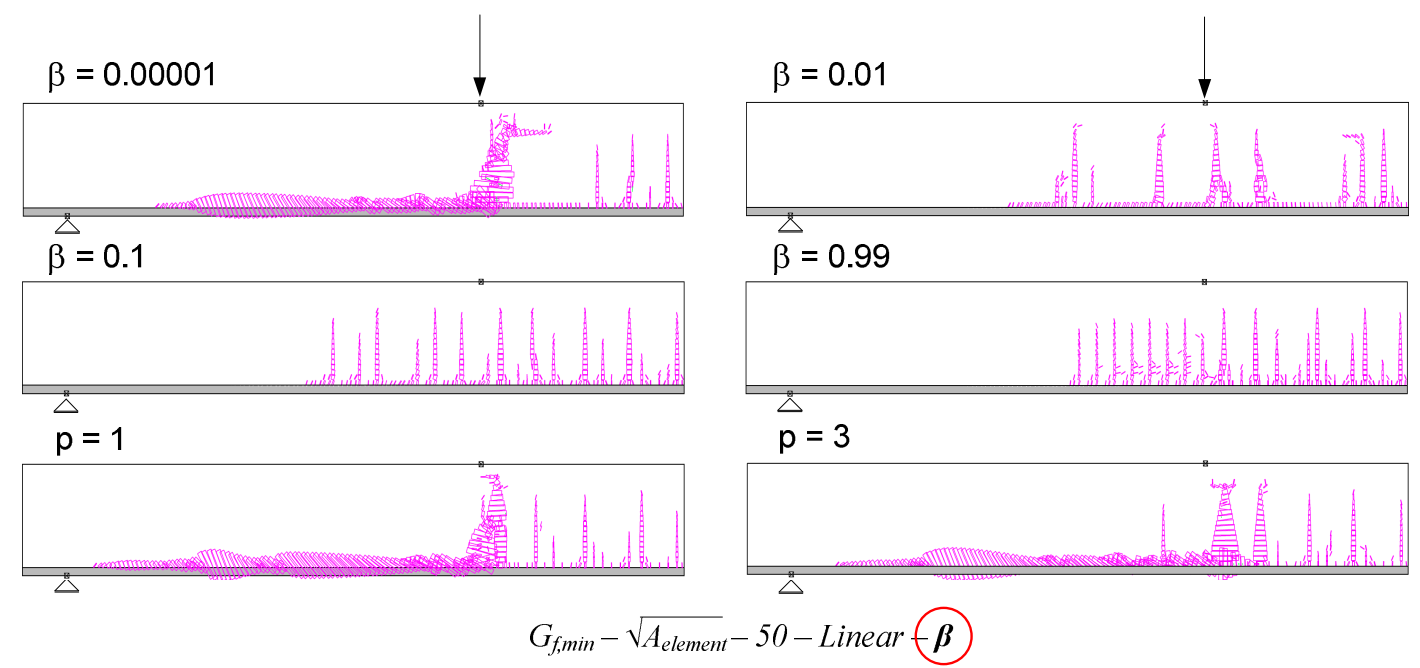

Fig. 18 - Effect of $\beta$ on the composite beam crack pattern $(\delta=13.75 \mathrm{~mm})$. Crack legend: closed (green), and fully-open (purple).

\subsubsection{Effect of adhesive's properties}

The previous sections addressed the implementation of a non-linear model to simulate the fracture behaviour of glass. Several parameters were calibrated in order to guarantee a stable and convergent model, capable of reproducing the fracture process on the glass-GFRP composite beams with perfect bond. After selecting the glass material model $^{14}$, the next step was to explicitly adopt a constitutive law for the adhesive joints aiming at the simulation of the composite glass beams bonded with an arbitrary adhesive. Fig. 19-a and -b compare the experimental flexural responses with the numerical results obtained from the $P B$ (not applicable to $R$-SFlex beams), PSE and $I E$ models.

\footnotetext{
${ }^{14} S G N L M M$ assumes $10 \times 10 \mathrm{~mm}^{2}, G_{f}=G_{f, \text { min }}, h=\sqrt{A_{\text {element }}}, f_{g, t}=50 \mathrm{MPa}$, linear tension-softening diagram, and $\beta=\left(1-\frac{\varepsilon_{n}^{c r}}{\varepsilon_{n, u l t}^{c r}}\right)^{2}$.
} 
Valarinho, L.; Sena-Cruz, J.; Correia, J.R.; Branco, F.A. (2017) "Numerical simulation of the flexural behaviour of composite glass-GFRP beams using smeared crack models." Composites Part B, 110: 336-350.

a)

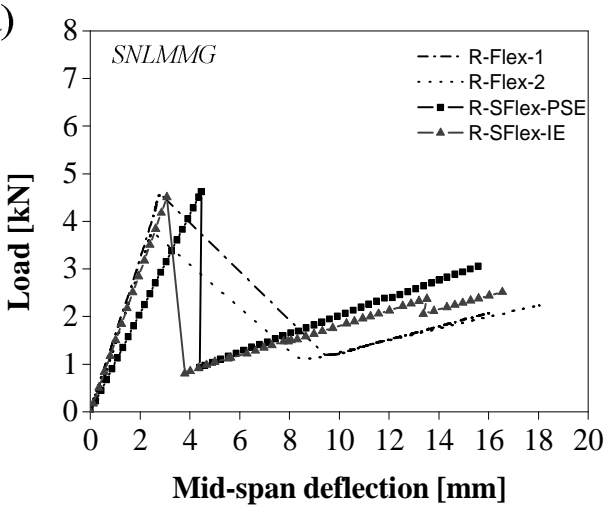

b)

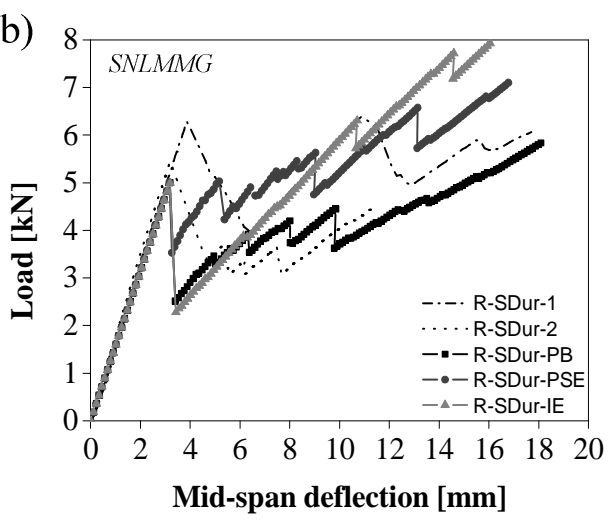

Fig. 19 - Experimental and numerical flexural behaviour of (a) R-SFlex and (b) $R$-SDur beams assuming: (i) no adhesive layer, (ii) plane stress elements, or (iii) interface elements to represent the adhesive layer.

Fig. 19-a shows that the PSE models underestimated the flexural stiffness of the R-SFlex beams (26.5\% lower than measured). This relative difference may be due to the experimental difficulty in accurately estimating the material properties of this very flexible and viscoelastic adhesive. Indeed, properties considered in this study were obtained from tensile tests, when the adhesive is subjected mostly to shear in the beam tests.

On the other hand, with the interface elements (IE model), the numerical response of the glass composite beams bonded with the SFlex adhesive was reproduced with much higher accuracy in terms of (i) initial stiffness (only 3.5\% higher than measured) and (ii) load reduction after the appearance of the first crack. In this regard, as mentioned, the differences to test data shall stem from the experimental measuring system, which was unable to capture with sufficient accuracy the complete path of the load drop.

In terms of crack pattern slight differences were found between the models used to simulate the $R$ SFlex beams response. Indeed, the numerical introduction of the adhesively bonded interface led to the appearance of a significantly lower number of cracks in both models when compared to the $P B$ model. However, only the PSE model succeeded in accurately simulating the localized crack pattern of the R-SFlex beams, which was characterized by the appearance and development of a single crack under the load application section (Fig. 20). The development of the crack pattern in the R-SFlex-IE 
Valarinho, L.; Sena-Cruz, J.; Correia, J.R.; Branco, F.A. (2017) "Numerical simulation of the flexural behaviour of composite glass-GFRP beams using smeared crack models." Composites Part B, 110: 336-350.

model was localized but restricted to three cracks instead of only one.

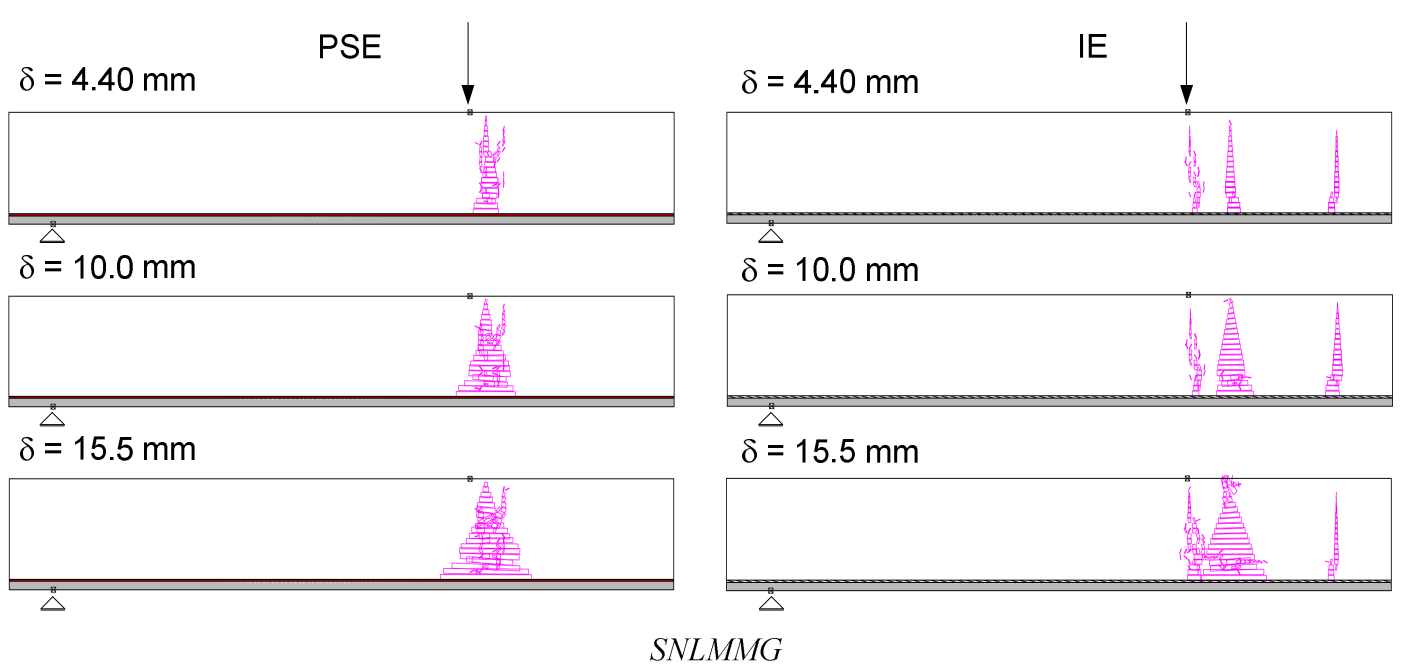

Fig. 20 - Crack pattern of R-SFlex beams when PSE or IE models were adopted to represent the adhesive layer. Crack legend: closed (green), and fully-open (purple).

Regarding the $R$-SDur beams, Fig. 19-b shows that the PSE models accurately estimated the initial stiffness of the composite beams and their cracking load. However, the post-cracking stage was not fully accurately captured; indeed, the models succeeded to simulate a progressive loss of stiffness and successive load drops, but yielded higher residual strength than the beams tested with the same cracking load. The models exhibited a shorter initial load drop, which affected the entire simulation, overestimating residual strength since the appearance of the first crack. As for the PSE models, it was expected that the introduction of interface elements simulating the adhesive layer would not impair the good accuracy already achieved with the $P B$ and $P S E$ numerical models. However, Fig. 19-b shows that the $I E$ models were able to accurately simulate the initial linear elastic stiffness, but were not so successful in capturing the second stage stiffness, as well as its progressive decrease during the crack propagation in the glass pane. Comparing the crack pattern of $R-S D u r-P B$ model with that of $R$-SDur-IE model, it is noticeable that some precision was lost (Fig. 21): for a displacement of $17.2 \mathrm{~mm}$, the numerical models were unable to present horizontal cracks or oblique shear cracks towards the supports. This may be due to the intrinsic limitations of the double-lap shear tests performed (DL-SDur specimens) in retrieving the complete response of the glass/SDur 
Valarinho, L.; Sena-Cruz, J.; Correia, J.R.; Branco, F.A. (2017) "Numerical simulation of the flexural behaviour of composite glass-GFRP beams using smeared crack models." Composites Part B, 110: 336-350.

adhesive/GFRP bonded interfaces of the composite beams, namely in representing the cracked stage of their flexural response $\mathrm{e}^{15}$.
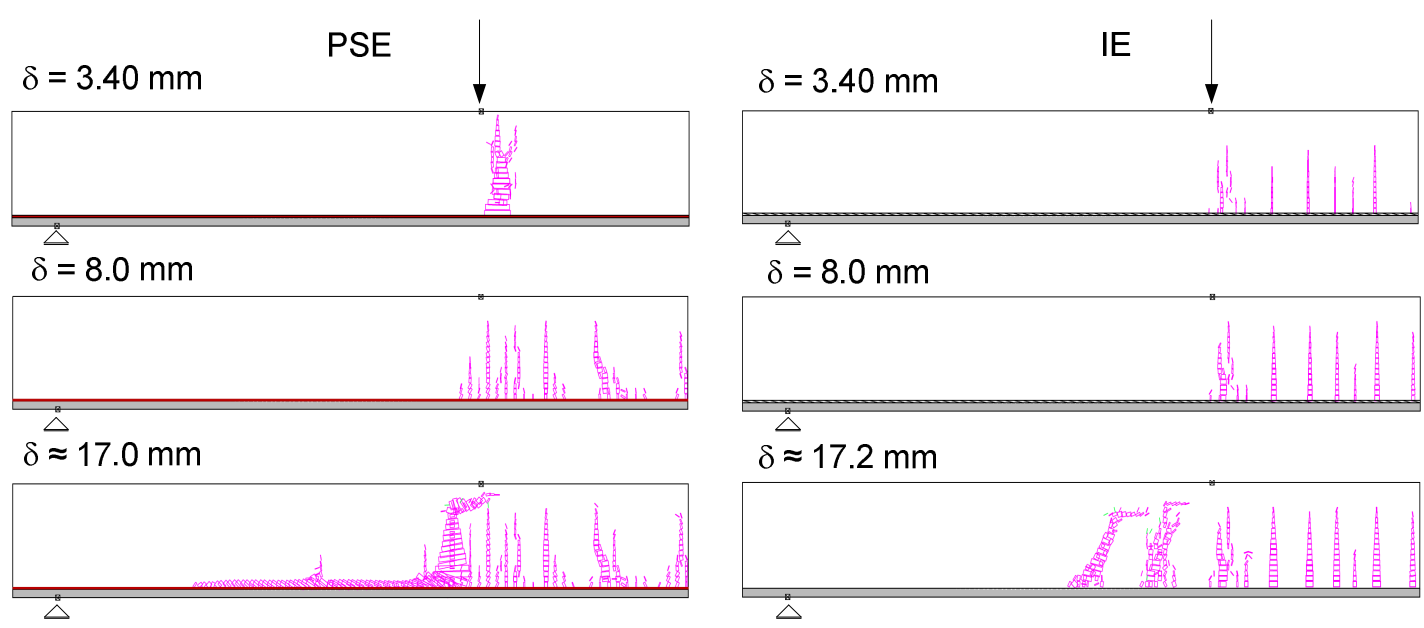

$S N L M M G$

Fig. 21 - Crack pattern of $R$-SDur beams with PSE (left) and IE (right) models representing the adhesive layer. Crack legend: closed (green), and fully-open (purple).

\section{Conclusions}

This paper presented a numerical study about the development of plane FE models able to simulate the flexural behaviour of rectangular glass-GFRP composite beams with two main objectives: (i) to calibrate a standard non-linear material model for glass according to the smeared crack approach (SCA); and (ii) to assess a suitable method to reproduce adhesively bonded joints of glass-GFRP composite beams.

The numerical models developed show that the SCA is able to reproduce glass fracture in composite beams and that the introduction of calibrated interface elements enhances the numerical models with bonded joints comprising soft adhesives.

The correct use of a standard model for glass requires the definition of several parameters. The numerical results that best fitted the experimental response were obtained when the following parameters were adopted: (i) tensile strength of $50 \mathrm{MPa}$; (ii) fracture energy $\left(G_{f}\right)$ equal to the

\footnotetext{
${ }^{15}$ Alternative experiments could involve single lap shear tests (to avoid "structural" redundancy), compressive loads (to prevent premature glass failure) and eventually cracked glass adherends to assess the influence of cracks in the stress transfer at the bonded interfaces.
} 
Valarinho, L.; Sena-Cruz, J.; Correia, J.R.; Branco, F.A. (2017) "Numerical simulation of the flexural behaviour of composite glass-GFRP beams using smeared crack models." Composites Part B, 110: 336-350.

minimum value necessary to avoid snap-back instability, available under a linear tension-softening diagram and combined with a quadratic shear retention factor law; (iii) crack band width equal to the square root of the finite elements' area (assuring mesh objectivity); (iv) threshold angle of $30^{\circ}$ for the development of new cracks; and (v) maximum number of two cracks per element.

It was shown that it is possible to simulate glass fracture considering a higher $G_{f}$ than the experimental value of $3 \mathrm{~N} / \mathrm{m}$. Indeed, the overall flexural behaviour of the glass-GFRP composite beams, characterized by a linear elastic pre-cracking stage and a brittle post-cracking stage, was successfully reproduced using $G_{f}$ in the range $3 \mathrm{~N} / \mathrm{m}$ to $300 \mathrm{~N} / \mathrm{m}$. Therefore, it seems that it is possible to simulate glass-GFRP composite beams without using highly discretized meshes, thus requiring less computation time and allowing the use of more practical and stable numerical models.

For the range considered in this study, changing the glass strength did not affect the overall behaviour of the composite beams, but retrieved different cracking loads, in line with the experimental observations (prone to glass scatter). Regarding the tension-softening diagram, the models showed that a better correlation is found when a linear shape (the one that minimizes $G_{f}$ ) is used. Finally, the study on the shear retention factor proved that non-constant values are suitable for the shear stress transfer after cracking.

Regarding the effect of using different adhesives to bond GFRP to glass, the accuracy of the different numerical approaches depended on the adhesive at stake. The joints bonded with the SFlex adhesive presented low levels of interaction (considerable slippage), which resulted in lower flexural stiffness and global strength, but enhanced post-cracking ductility [28]. The most accurate numerical predictions of the aforementioned behaviour were obtained by simulating the adhesive joint using interface elements with the following constitutive law: exponential shear law $(\alpha=0.90)$, with peak point at a slippage of $s_{m}=4.20$ and $\tau_{m}=1.70 \mathrm{MPa}$ and with normal stiffness of $K_{n}=10^{6} \mathrm{kN} / \mathrm{m}^{3}$. On the other hand, the composite beams bonded with the SDur adhesive presented high levels of interaction with negligible slip at the interfaces. Therefore, for these beams, the most accurate models were those in which the adhesive was not represented and perfect bond between glass and GFRP was considered. 
Valarinho, L.; Sena-Cruz, J.; Correia, J.R.; Branco, F.A. (2017) "Numerical simulation of the flexural behaviour of composite glass-GFRP beams using smeared crack models." Composites Part B, 110: 336-350.

\section{Acknowledgements}

The authors wish to acknowledge FCT, ICIST/CERIS and ISISE for funding the research, and companies SIKA, Guardian and ALTO for supplying the adhesives, the glass panes and the GFRP pultruded profiles used in the experiments. The first author also wishes to thank FCT for the financial support through his $\mathrm{PhD}$ scholarship SFRH/BD/80234/2011.

\section{References}

[1] Martens K, Caspeele R, Belis J. Development of composite glass beams - A review. Eng Struct 2015;101:1-15.

[2] Martens K, Caspeele R, Belis J. Development of Reinforced \& Post-Tensioned Glass Beams - Review. J Struct Eng 2015:1-23.

[3] Cruz JS, Barros J, Azevedo Á, Gouveia a V. Numerical Simulation of the Nonlinear Behavior of Rc Beams Strengthened With Nsm Cfrp Strips. C. 2007 - Congr. Numer. Methods Eng. XXVIII CILAMCE - Iber. Lat. Am. Congr. Comput. Methods Eng., 2007, p. 13-5.

[4] Ølgaard AB, Nielsen JH, Olesen JF. Design of Mechanically Reinforced Glass Beams : Modelling and Experiments. Struct Eng Int 2009;19:130-6.

[5] Louter C, Nielsen JH. Numerical analyses of the effect of SG-interlayer shear stiffness on the structural performance of reinforced glass beams. In: Belis J, Louter C, Mocibob D, editors. COST Action TU0905, Mid-term Conf. Struct. Glas., vol. 1, Porec, Croatia: 2013, p. 405-12.

[6] Louter CLPC. Fragile yet Ductile - Structural Aspects of Reinforced Glass Beams. PhD dissertation, Delf University of Technology, 2011.

[7] Louter C, Belis J, Veer F, Lebet J-P. Structural response of SG-laminated reinforced glass beams; experimental investigations on the effects of glass type, reinforcement percentage and beam size. Eng Struct 2012;36:292-301.

[8] Bazant ZP, Oh BH. Crack band theory for fracture of concrete. Mater Struct 1983;16:155-77.

[9] Nakayama J. Direct Measurement of Fracture Energies of Brittle Heterogeneous Materials. J Am Ceram Soc 1965;48:583-7.

[10] Outwater JO, Gerry DJ. On the Fracture Energy of Glass. NRL Interim Contract Report. University of Vermont, Burlington, Vt.: 1966.

[11] Wiederhorn SM. Fracture Surface Energy of Glass. J Am Ceram Soc 1969;52:99-105.

[12] Haldimann M, Luible A, Overend M. Structural use of glass. Zurich: IABSE-AIPC-IVBH; 2008.

[13] Bedon C, Louter C. Exploratory numerical analysis of SG-laminated reinforced glass beam experiments. Eng Struct 2014;75:457-68.

[14] Modéer M. A fracture mechanics approach to failure analyses of concrete materials. PhD Dissertation, Lund Technical University, Sweden, 1979.

[15] Petersson P-E. Crack growth and development of fracture zones in plain concrete and similar materials. PhD Dissertation, Lund Technical University, Sweden, 1981.

[16] Sena-Cruz JM. Strengthening of concrete structures with near-surface mounted CFRP laminate strips. PhD dissertation, University of Minho, Portugal, 2004.

[17] Neto P, Alfaiate J, Valarinho L, Correia JR, Branco FA, Vinagre J. Glass beams reinforced with GFRP laminates: Experimental tests and numerical modelling using a discrete strong discontinuity approach. Eng Struct 2015;99:253-63.

[18] Correia JR, Valarinho L, Branco FA. Post-cracking strength and ductility of glass-GFRP composite beams. Compos Struct 2011;93:2299-309.

[19] Valarinho L, Correia JR, Branco FA. Experimental study on the flexural behaviour of multi-span transparent glass-GFRP composite beams. Constr Build Mater 2013;49:1041-53.

[20] ISO 527 Plastics - Determination of the tensile properties - Part 1: General principles. International Organization for Standardization, Genève: 1993. 
Valarinho, L.; Sena-Cruz, J.; Correia, J.R.; Branco, F.A. (2017) "Numerical simulation of the flexural behaviour of composite glass-GFRP beams using smeared crack models." Composites Part B, 110: 336-350.

[21] ISO 527 Plastics - Determination of the tensile properties - Part 4: Test conditions for isotropic and orthotropic fibre-reinforced plastic composites. International Organization for Standardization, Genève: 1997.

[22] ISO 37 Rubber, vulcanized or thermoplastic - Determination of tensile stress-strain properties. International Organization for Standardization, Genève: 2011.

[23] ISO 527 Plastics - Determination of the tensile properties - Part 2: Test conditions for moulding and extrusion plastics. International Organization for Standardization, Genève: 1993.

[24] Valarinho L, Correia JR, Branco FA, Sena-Cruz J. Experimental and numerical study on GFRP-glass adhesively bonded joints. In: Louter, Bos B\& L (Eds), editor. Challenging Glas. 4 COST Action TU0905 Final Conf., Taylor \& Francis Group, London; 2014, p. 393-400.

[25] Martens K. Numerical investigation of two-sided reinforced laminated glass beams in statically indeterminate systems. Glas Struct Eng 2016.

[26] Report EUR 26439 EN Guidance for European Structural Design of Glass Components. Institute for the Protection and Security of the Citizen, Joint Research Centre, Luxembourg: 2014.

[27] Cornelissen HAW, Hordijk DA, Reinhardt HW. Experimental determination of crack softening characteristics of normalweight and lightweight concrete. Heron 1986;31:45-56.

[28] Valarinho L, Correia JR, Branco F, Sena-Cruz J. Experimental investigations on continuous glassGFRP Beams. Preliminary non-linear numerical modelling. In: Bos, Louter, Nijsse V, editor. Challenging Glas. 3 Conf. Archit. Struct. Appl. Glas., Delft: Amesterdam: IOS Press; 2012, p. 745-58.

[29] CNR-DT 210/2013 Istruzioni per la Progettazione, l'Esecuzione ed il Controllo di Costruzioni con Elementi Strutturali di Vetro. Consiglio Nazionale Delle Ricerche, Roma: 2013.

[30] The Institution of Structural Engineers. Structural use of glass in buildings (Second edition). London: The Institution of Structural Engineers (ISE); 2014.

[31] Bažant Z. Fracture in concrete and reinforced concrete. In: Ltd. JW\& S, editor. Mech. Geomaterials Rocks, Concr. Soils, 1985, p. 259-303.

[32] Veer FA, Louter PC, Bos FP. The strength of annealed, heat-strengthened and fully tempered float glass. Fatigue Fract Eng Mater Struct 2009;32:18-25.

[33] Vandebroek M, Louter C, Caspeele R, Ensslen F, Belis J. Size effect model for the edge strength of glass with cut and ground edge finishing. Eng Struct 2014;79:96-105. 